\title{
Situation analysis of the integration of family planning services in postpartum, postabortion and prevention of mother to child transmission programs in Nicaragua
}

Freddy Solis

Ana del Carmen Rojas

Gadea Adilia

M. Estela Rivero-Fuentes

Population Council

Ricardo Vernon

Population Council

Follow this and additional works at: https://knowledgecommons.popcouncil.org/departments_sbsr-rh

Part of the Immune System Diseases Commons, International Public Health Commons, Maternal and Child Health Commons, Obstetrics and Gynecology Commons, Social and Behavioral Sciences Commons, Virus Diseases Commons, and the Women's Health Commons How does access to this work benefit you? Let us know!

\section{Recommended Citation}

Solis, Freddy, Ana del Carmen Rojas, Adilia Gadea, M. Estela Rivero-Fuentes, and Ricardo Vernon. 2008. "Situation analysis of the integration of family planning services in postpartum, postabortion and prevention of mother to child transmission programs in Nicaragua," FRONTIERS Final Report. Washington, DC: Population Council. 


\title{
Situation Analysis of the Integration of Family Planning Services in Postpartum, Postabortion and Prevention of Mother to Child Transmission Programs in Nicaragua
}

\author{
ALVA \\ Freddy Solis \\ Ana del Carmen Rojas \\ Adilia Gadea \\ FRONTIERS \\ Ma. Estela Rivero-Fuentes \\ Ricardo Vernon
}

\section{March 2008}

This study was made possible by the generous support of the American people through the United States Agency for International Development (USAID) under the terms of Cooperative Agreement No. HRN-A-00-98-00012-00 and Subagreement Number A105.56A. The contents are the responsibility of the FRONTIERS Program and do not necessarily reflect the views of USAID or the United States Government. 


\section{EXECUTIVE SUMMARY}

Between September 2005 and April 2007, FRONTIERS and Alva, a Nicaraguan consulting firm, conducted a situation analysis of the provision and use of contraceptive services in postpartum, postabortion and prevention of mother-to-child transmission of HIV (PMTCT) programs. This study was undertaken in collaboration with the Nicaraguan Ministry of Health $(\mathrm{MOH})$ and the Nicaraguan Social Security Institute (INSS). The project's objective was to assess the degree to which contraceptive services were linked to postpartum, postabortion and PMTCT services and if this allowed the programs to meet the contraceptive needs of their clients. The project also proposes recommendations for improving the quality of these programs.

The study collected quantitative and qualitative data from a nationally representative sample of $11 \mathrm{MOH}$ hospitals, $20 \mathrm{MOH}$ health centers and three Provisional Medical Companies (EMPs) that were affiliated to the National Social Security Institute (INSS) of Nicaragua. Data collection took place between June and September 2006 through service inventories from 33 clinics, interviews with 75 providers in primary care facilities, 156 providers in secondary care health units, 596 women in antenatal care, 487 women before discharge from the hospital after a delivery, 26 women who had received postabortion care; and 605 women in the six-months postpartum period visiting out-patient clinics and health centers. Two focus group discussions were held with women seeking postpartum care in a health facility, two with women that were in the six month postpartum period but had not sought postpartum care, and one with women who were living with HIV. In-depth interviews were held with $\mathrm{MOH}$ directors in charge of family planning, post-obstetric care and PMTCT, and with reproductive health experts at the national and local levels.

The study yielded the following key findings:

1. MOH health centers were well prepared for offering family planning services during antenatal care and in the extended postpartum period. Most health centers offered a variety of methods and had IEC materials. Their staff were aware of the national service delivery guidelines; they had also received training on family planning counseling and methods, and were knowledgeable about breastfeeding and the return of fertility after delivery. The most important problems affecting family planning services at this level were contraceptive method stock-outs and inadequate referral and counter-referral mechanisms.

2. Compared to health centers, $\mathrm{MOH}$ hospitals were less prepared for providing family planning services to postpartum women. There was less awareness of national service delivery guidelines, IEC materials were scarcer and many providers did not know about the effect of exclusive breastfeeding on fertility. Hospitals also had method stock-outs, particularly of IUDs and injectables, two methods that can be provided immediately after delivery according to the National Family Planning Guidelines.

3. Of the $11 \mathrm{MOH}$ hospitals visited, nine provided family planning services during postabortion care (PAC). Providers involved in this service had been trained in family planning counseling and the technical aspects of methods, but half of them did not know when fertility returned after post-abortion care. 
4. Of three EMPs included in this study, two offered limited family planning services, mainly counseling during antenatal care and only one method before discharge from the hospital after delivery: injectables in one case and female sterilization in the other. None of the EMPs offered contraceptive methods before discharge from the hospital after PAC.

5. Practically all the women interviewed during the perinatal period and following postabortion care wanted to space their next pregnancy for at least two years or did not want any more children.

6. One of every two women received family planning counseling during antenatal care; 64 percent received it during their hospital stay for delivery; and 44 percent during maternal and child health visits in the six months after delivery. In the case of postabortion women, 39 percent received family planning counseling before hospital discharge. All these percentages were lower among women attending EMPs.

7. $\mathrm{MOH}$ establishments missed important opportunities for providing family planning services during postpartum and postabortion care. Four of every 10 women interviewed at hospitals received a contraceptive method before discharge after a delivery; however, onehalf of those who did not receive a method would have liked to get one. Similar results were found in the case of postabortion care: one of every three women received a method before hospital discharge, and 59 percent of those who did not would have liked to get one.

8. Less educated women, women in stable unions and women who had three children or more were more likely to receive counseling and methods during antenatal care and during their hospital stay for delivery than women who were single, more educated and had less than three children.

9. At least 16 percent of the women in the six-month postpartum period were exposed to the risk of an unplanned pregnancy because they were not using a contraceptive method, had stopped breastfeeding, and their menses had returned.

10. Family planning counseling during hospital stays for delivery and during maternal and child visits to health centers in the six months after delivery had a greater effect on contraceptive use in the six-month postpartum period than family planning counseling during antenatal care.

11. MOH health units were missing opportunities to provide the IUD to postpartum and postabortion clients. When asked what contraceptive method they would like to use after delivery, 17 percent of the women interviewed during antenatal care mentioned IUDs. However, only 6 percent of the women interviewed in the six-month postpartum period were using this method. Although $\mathrm{MOH}$ service delivery units were well prepared for offering this service, trained providers often do not conduct insertions.

12. Health units have made an important effort to implement PMTCT activities during antenatal care, but more needs to be done. Eighteen of the 19 health centers where an inventory was completed said that they offered PMTCT counseling during antenatal care, and 14 said that they offered voluntary testing for pregnant women. However, only one in every four women interviewed during antenatal care said that they had received HIVrelated information during their visits.

13. The two hospitals that served as national referral centers for HIV+ women had a PMTCT program that included HIV testing, C-sections, antiretrovirals for the mother and the child, 
and breastfeeding substitution with formula. In addition, several regional hospitals had implemented PMTCT programs that included some of these activities.

14. Focus-group discussions with HIV+ women showed that there is a need to increase their access to family planning services. All these women were using condoms as a contraceptive method, but they stated that they did not feel completely safe with the method. When they have asked for alternative contraceptive options, their health providers have discouraged them and some even asked them to stop the use of other methods.

Key recommendations to improve the linkages between family planning and postpartum and postabortion services include:

a) Increase the role of nurses and nurse auxiliaries in maternity and Ob-Gyn wards in the delivery of family planning counseling and contraceptive methods.

b) Conduct refresher training for all staff involved in family planning, postpartum and postabortion care.

c) Develop or adapt IEC materials, including check-lists, which remind health providers of the family planning methods that are recommended for postpartum and postabortion women, and of other information that they should give pregnant and postpartum women during their visits.

d) Organize campaigns to highlight the safety and convenience of inserting an IUD postpartum and postabortion to encourage staff already trained to provide the method.

e) Improve the referral and counter-referral mechanisms between service delivery units at the primary and secondary level of care.

f) Develop a mechanism to identify women with unmet need for family planning during their post-delivery maternal and child visits to outpatient services.

g) Work with the INSS to convince EMPs of the importance of postpartum and postabortion family planning. 
Recommendations to improve PMTCT services include:

a) Conduct PMTCT counseling sessions routinely in the waiting areas of health centers where women are waiting to have antenatal care.

b) Inform all women in antenatal care of the tests that they are going to have and give them the option to opt out of HIV testing.

c) Remind health providers in clinics where HIV+ women receive most of their health care of the importance of family planning and of the eligibility criteria for contraceptive methods for this population.

The findings in this report were shared with the Nicaraguan $\mathrm{MOH}$, who used them to formulate the workplan for the administration that took over in 2007. They were also presented to the representatives of the $\mathrm{MOH}$ HealthCare Improvement project and NicaSalud during a regional workshop in October 2007. At the end of the workshop these representatives agreed to work together and follow up with national and local authorities as well as other cooperating agencies, in order to use these results as an input for a plan to improve postabortion, postpartum and PMTCT services. 


\section{TABLE OF CONTENTS}

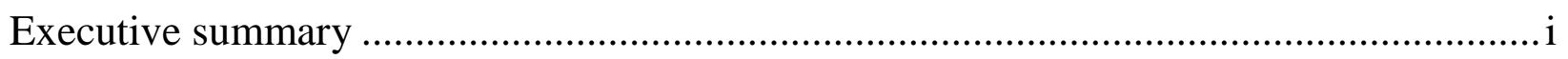

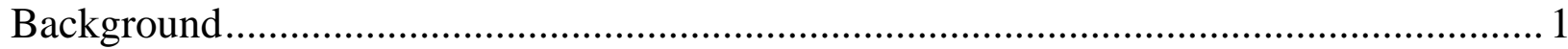

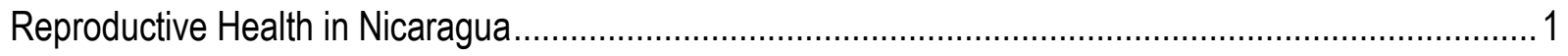

Organization and Coverage of Health Care Services ....................................................................

Postpartum and Postabortion Contraception in Nicaragua ............................................................... 4

Prevention of Mother-to-Child Transmission of HIV (PMTCT) ..........................................................

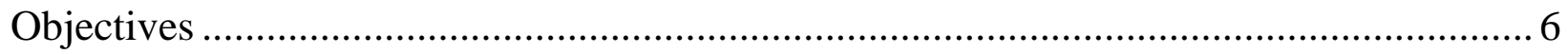

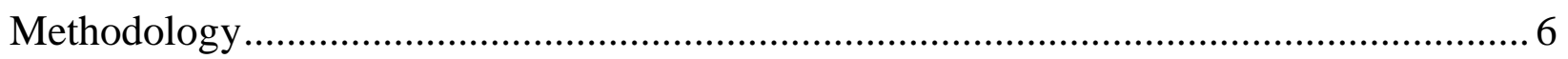

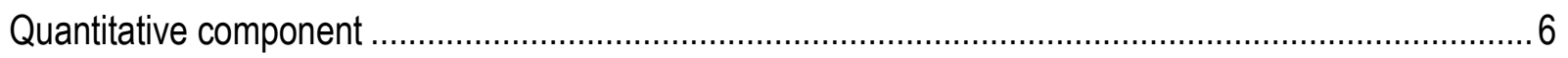

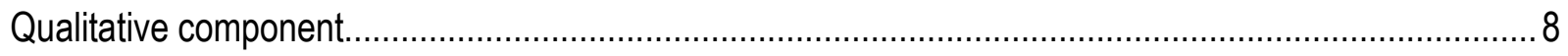

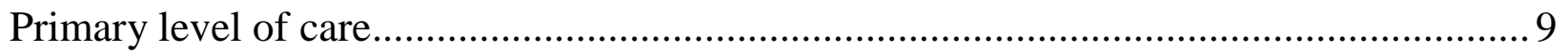

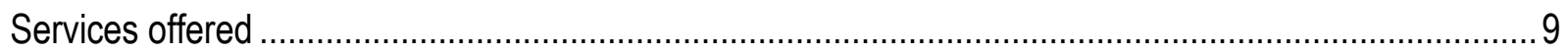

Resources for family planning services ......................................................................................

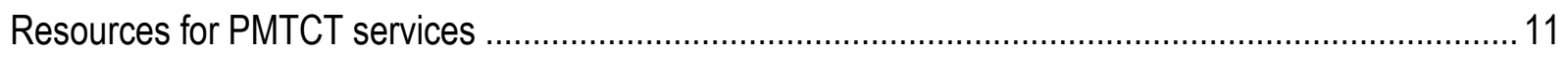

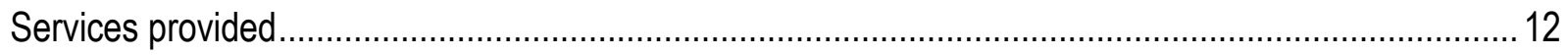

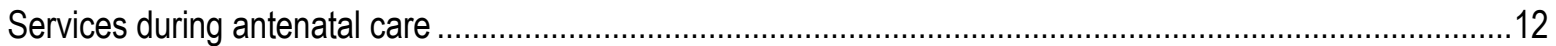

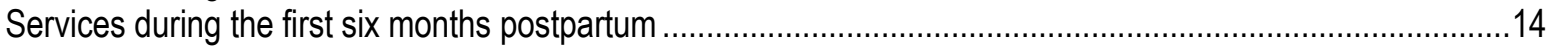

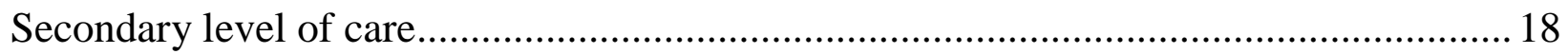

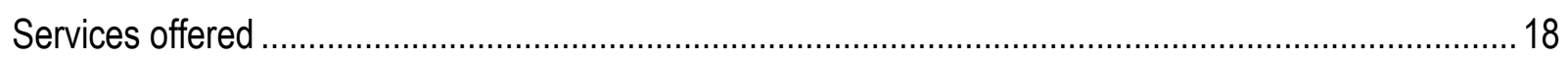

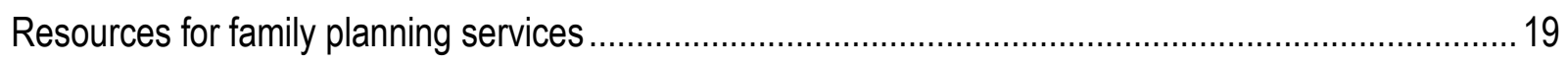

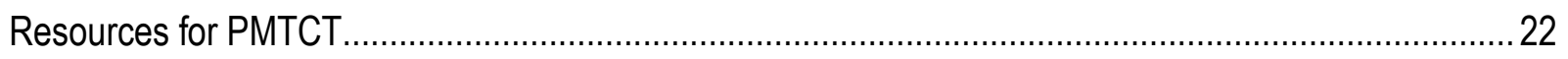

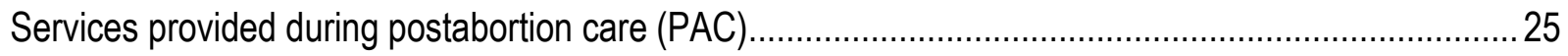

PMTCT and family planning needs of women living with HIV ....................................2

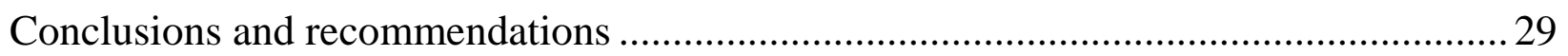




\section{BACKGROUND}

\section{Reproductive Health in Nicaragua}

Nicaragua is located in the central region of Latin America and has, according to the most recent (1995) census 4,357,099 inhabitants ${ }^{1}$. Politically and administratively, the country is divided in 15 departments and 2 autonomous regions. The crude death rate (CDR) is estimated at 5 per 1,000 inhabitants $^{2}$ and life expectancy at 69 years ${ }^{3}$. WHO estimates a maternal mortality ratio (MMR) of 230 deaths per 100,000 births ${ }^{4}$, but national estimates yield a MMR of 107 deaths per 100,000 births $^{5}$. A 1998 study about the causes of maternal deaths found that approximately 52 percent of maternal deaths were due to hemorrhage, 23 percent to high blood pressure and 9 percent to unsafe abortions.

Close to 86 percent of all pregnant women attend at least one antenatal care visit; $90 \%$ receive qualified care during childbirth and 66 percent have an institutional delivery. In rural areas, institutional delivery is estimated at 45 percent, while in Managua, the capital city, it is 94 percent ${ }^{6}$. The most recent estimates indicate that every year there are 32,000 abortions ${ }^{7}$ and 5,500 admissions in health care services to receive postabortion care $(\mathrm{PAC})^{8}$. UNFPA ${ }^{9}$ estimates that in 1998 there were 6,000 unsafe abortions and the Global Health Council estimated a mortality rate due to abortions of 86 per every 100,000 abortions ${ }^{10}$. Between 1970 and 2001 Nicaragua experienced a sharp fertility decline. In the period 1970-1975, the total fertility rate (TFR) was 6.8 children for every woman in the fertile age ${ }^{11}$; by 2001 the TFR was $3.2^{12}$. In urban areas the TFR is 2.6 children per woman, compared to 4.4 in rural areas ${ }^{13}$.

\footnotetext{
${ }^{1}$ Nicaragua. INEC. 1996. VII Censo Nacional de Población y III de Viviendas - 1995. Informe final.

${ }^{2}$ UN Population Division. Demography Yearbook. (Consulted online on January 19, 2007).

3 The World Bank. 2005. World Development Indicators. Washington, DC.

${ }^{4}$ The World Bank. 2005. World Development Indicators. Washington, DC.

5 Padilla, K and McNaughton, H. 2003. La mortalidad materna en Nicaragua: una mirada rápida a los años $2000-$ 2003. IPAS. Centro América.

6 ORC Macro, 2007. MEASURE DHS STAT compiler. http://wwW.measuredhs.com, consulted online January 23, 2007.

7 Global Health Council, 2000. Promises to Keep. The Toll of Unintended Pregnancies in Women's Lives in the Developing World.

${ }^{8}$ MINSA. 2003. Un Diagnóstico Nacional de la Atención Postaborto.

${ }^{9}$ UNFPA. 2000. Estado de la Población Mundial, Resumen 2000. Informe Nacional de Nicaragua, pp. 33.

${ }^{10}$ Global Health Council, 2000. Promises to Keep. The Toll of Unintended Pregnancies in Women's Lives in the Developing World.

${ }^{11}$ Nicaragua. Política Nacional de Población.

12 ORC Macro, 2007. MEASURE DHS STATcompiler. http://wWW.measuredhs.com, consulted online January 23, 2007.

13 ORC Macro, 2007. MEASURE DHS STATcompiler. http://www.measuredhs.com, consulted online January 23, 2007.
} 
According to the 2001 DHS, 69 percent of women in fertile age use a contraceptive method. This use varies according to the department and geographical region: in Estelí, León and Carazo, three of the richest departments in the country, contraceptive use is greater than 75 percent. By contrast, contraceptive use in the North-Atlantic Autonomous Region (RAAN), one of the poorest departments, is 46 percent $^{14}$. The contraceptive methods most commonly used are female sterilization (26\%); oral contraceptives (15\%); injectables (15\%); IUDs $(6 \%)$ and the male condom $(6 \%)$. All other methods are used by less than 1 percent of women in fertile age ${ }^{15}$.

HIV in Nicaragua is still concentrated in groups with high-risk behaviors, although the number of HIV+ cases has been increasing since 1987, when the first case was detected. According to the Ministry of Health's National STI/HIV/AIDS Program, there had been 1602 cases until March of $2005^{16}$. In the same year, the annual incidence rate of this infection was 8.24 per 100,000 , which implied an increase from the 2000 rate $(2.52$ per 100,000$)$. The regions with the greatest reported prevalence rates are Chinandega, Managua and the South-Atlantic Autonomous Region (RAAS), with 74.1, 65.3, and 37.7 cases per 100,000 inhabitants, respectively. Of the cases reported, 73 percent are men and 27 percent are women. In both cases, the greatest concentration occurs in the 25-29 age group. As for the mode of transmission, 92 percent of the cases were due to sexual transmission (73\% of these among heterosexuals), and only 3 percent of the cases were due to perinatal transmission ${ }^{17}$.

Mother-to-child transmission of HIV among women who receive antenatal care was estimated at 0.5 percent. The cumulative number of pregnant HIV+ women until June 2005 was 62, half of which were between 15 and 23 years old, while the cumulative number of perinatal transmissions was $54^{18}$. In 2005, 2,800 tests were made on women attending prenatal care and two positives were obtained. ${ }^{19}$

${ }^{14}$ ORC Macro, 2007. MEASURE DHS STATcompiler. http://www.measuredhs.com, consulted online January 23, 2007.

15 ORC Macro, 2007. MEASURE DHS STATcompiler. http://www.measuredhs.com, consulted online January 23, 2007.

${ }^{16}$ MINSA. 2005. Vigilancia Epidemiológica de ITS/VIH/SIDA. Nicaragua. Año 2005. Power point presentation.

${ }^{17}$ República de Nicaragua. 2006. Plan Estratégico Nacional de ITS/VIH/SIDA. Nicaragua 2006-2010. Managua, Nicaragua.

${ }^{18}$ UNAIDS. 2007. Nicaragua Fact Sheet; (http://www.unaids.org/en/Regions_Countries/Countries/nicaragua.asp; consulted online January 30, 2007.

${ }^{19}$ Programa Nacional de ITS/VIH/SIDA.2005. Vigilancia Epidemiológica de ITS/VIH/SIDA Nicaragua. Año 2005., and personal conversation with Dra. Alma Fabiola Morales, Reproductive, Sexual and Adolescent Health officer, PAHO, Nicaragua. August 26, 2005. 


\section{Organization and Coverage of Health Care Services}

The health care sector has public and private providers. The public sector is represented by the Ministry of Health (MOH, or MINSA by its Spanish acronym), the Nicaraguan Institute of Social Security (INSS), and the Ministry of the Interior and the Ministry of Defense. The private sector includes hospitals, provisional clinics and non-governmental organizations.

The INSS covers slightly more than 11 percent of the population, including formal workers, their children who are younger than 13 years old, and their wives during pregnancy and the first 40 days postpartum. Reproductive health services covered by the INSS include family planning, but only for the direct beneficiary, not for his wife. It also covers antenatal care, institutional delivery and postpartum checkups. Since the beginning of health sector reform, the INSS has acted solely as a financial agency. Health services are provided by 48 "Provisional Medical Companies" (Empresas Médicas Provisionales, or EMPs); whom the INSS pays close to US\$12.50 per year for each person insured. The worker selects the EMP he or she prefers. Many of these EMPs have their own facilities. However, nearly 25 percent of EMPs (which cover $40 \%$ of the population) sublet MOH's hospital facilities and subcontract $\mathrm{MOH}$ personnel to provide services. Seven companies cover 50 percent of the total people insured, all of them located in Managua. During 2004, EMPs attended 10,766 births, of which 51 percent were caesarean sections.

$\mathrm{MOH}$ hospitals, health centers and health posts cover the population that is not affiliated to the INSS, independently affiliated to an EMP, or to the Ministry of Defense. These are usually the unemployed, informal workers, self-employed and their families, which means that the MOH serves the poorest population in the country. In 1990 the MOH decentralized its services and created 17 Local Integral Health Care Systems (Sistemas Locales de Atención Integral a la Salud, or SILAIS), responsible for providing services to the population. Every SILAIS has a minimum of one hospital, five health centers and 20 health posts. Overall, the MOH has 32 hospitals, one polyclinic (located in Managua), 25 health centers with beds, 150 health centers without beds and 862 health posts. ${ }^{20} \mathrm{MOH}$ 's 32 hospitals are centrally managed by the Direction of Hospitals and related at the local level to health centers and posts. Of the 32 hospitals, 20 provide obstetric care (17 departmental hospitals and 3 in the Managua region). In 2004, MOH hospitals attended 63,987 births, of which 31 percent were reported as caesarean sections. Twelve of these 20 hospitals attended 82 percent of total births. ${ }^{21}$

A 2003 study showed that 85 percent of the 47 health units equipped to provide the service were offering postabortion care ${ }^{22}$. The units that were not offering the service were all ambulatory health centers in the Pacific region. Of the units that had the service available, all but seven offered manual vacuum aspirations (MVAs). In addition, twenty units did not have complete equipment. The same study showed that the main weaknesses of postabortion care were

\footnotetext{
${ }^{20}$ Oficina de Estadística/CNS. 2004. Red de Servicios al 30 de junio 2004. República de Nicaragua. Ministerio de Salud. División General de Planificación y Desarrollo.

21 MINSA. 2005. Consolidado anual de cuadro de mando 2004.

22 Padilla, K and McNaughton, H. 2003. La mortalidad materna en Nicaragua: una mirada rápida a los años 20002003. IPAS. Centro América.
} 
insufficient linkages with other health services, including family planning and the incomplete or non-existent statistics in most units.

The public sector is the main provider of contraceptive methods in the country (64\% of all users). Within the private sector, the most important providers are pharmacies (12\% of users) and Profamilia, the IPPF/WHR affiliate in the DR (9\% of users) ${ }^{23}$. The private sector is the main provider of vasectomies ( 8 of every 10). Half of all the condoms used in the country are distributed in the private sector and half in the public sector.

\section{Postpartum and Postabortion Contraception in Nicaragua}

Postpartum and postabortion contraception has been one of the main family planning strategies fostered by the MOH in Nicaragua since 1994 to space pregnancies by at least two years, prevent second adolescent pregnancies, and diminish maternal and perinatal morbidity and mortality rates, especially among women who do not have easy access to medical services. ${ }^{24}{ }^{25}$ In Nicaragua, these two services are jointly referred to as post-obstetric event contraception (POEC), defined as the provision of contraceptive methods after delivery, abortion, molar or ectopic pregnancy or during a cesarean section.

In 1994, a group of Ob-Gyn doctors and nurses created the first Guidelines for IUD Postpartum, Postabortion and Transcaesarean Insertion (Pautas de Inserción de DIU Posparto-Posaborto y Transcesárea ${ }^{26}$ and national training centers were later created in the Bertha Calderón and Oscar Danilo Rosales hospitals. Although training was extended to all hospitals, many of them did not implement the strategy. In 1999 the MOH, with the support of UNFPA, strengthened implementation of the strategy through the installation of family planning clinics in nine departments in the country. Currently, post-obstetric family planning should be offered wherever care is provided for obstetric events.

The MOH recently revised its National Family Planning Guidelines with the support of USAID (through the MAQ initiative and the Quality Assurance Project) and UNFPA. The last version of these guidelines, published in 2004, included a chapter on post-obstetric contraception, which explained that postpartum women were eligible for all contraceptive methods, with the exception of combined hormonals. The new version emphasizes the role of family planning counseling during antenatal care and the provision of contraceptives in institutions that provide postpartum and postabortion care.

In 2004, the MOH started an effort to collect post-obstetric contraception indicators in its hospital network. Basic indicators collected include: 1) the proportion of women that leave the health unit

\footnotetext{
23 ORC Macro, 2007. MEASURE DHS STATcompiler. http://www.measuredhs.com, consulted online January 23, 2007.

${ }^{24}$ MINSA, Manual de Anticoncepción Post Evento Obstétrico, DGSS, DAIMNA. Karla Aburto Hernández, Carolina Arauz - 1a Edición - 2001

${ }^{25}$ MINSA. Anticoncepción posparto. 1994

${ }^{26}$ MINSA. Anticoncepción posparto. 1994
} 
after an obstetric event using a contraceptive method; 2) the distribution of these women according to the method used; and 3) the percentage of women referred to other units to receive contraception. At the time of this study, this information was available for a number of hospitals in the $\mathrm{MOH}$ system, although among those that did report the information it was frequent to find that over 40 percent of women admitted for delivery or postabortion complication care received a method before discharge. A study of postabortion care carried out in 2003 showed that clients frequently did not have access to contraceptive methods, especially during the night and weekend shifts ${ }^{27}$.

\section{Prevention of Mother-to-Child Transmission of HIV (PMTCT)}

The National Guidelines for Antiretroviral Treatment ${ }^{28}$ specify the actions that should be followed during antenatal, delivery and postpartum care to decrease the number of infant HIV infections. These include:

- Offering HIV voluntary counseling and testing during the first visit to all women who receive antenatal care in $\mathrm{MOH}$ units.

- Women who are detected as being HIV+ and in the AIDS phase should be referred to the Hospital Bertha Calderón for their subsequent antenatal care visits and for delivery.

- Women who are detected as being HIV+ but not in the AIDS phase should continue their antenatal care in their local health center.

- HIV+ pregnant women should be tested regularly for CD4 counts and the presence of opportunistic infections. These women should also receive Zidovudine after the $14^{\text {th }}$ week.

- Programmed, elective caesarean sections for HIV+ women.

- Providing family planning counseling for HIV+ pregnant women during the third trimester.

- If labor lasts longer than four hours, HIV+ women should receive a dosage of Nevirapine and AZT.

- All the babies of HIV+ women should receive a dosage of AZT and 3TC within the first 48 hours of childbirth.

- Support alternative nutrition through counseling and free breast milk substitutes.

In addition, the National STI/HIV/AIDS program specifies that PMTCT activities should increase access to adequate family planning services among women living with HIV. In order to achieve this, the program seeks to: 1 ) provide family planning information to HIV+ women of fertile age; 2) increase access to free or low-cost safe contraceptive alternatives; and 3) design and implement a program of female sterilization for women living with HIV ${ }^{29}$. Operationally, the National STI/HIV/AIDS program is decentralized in 17 SILAIS, with focus points in each municipality. Each municipality has a person in charge of HIV/AIDS (who usually also has

\footnotetext{
${ }^{27}$ Padilla, K and McNaughton, H. 2003. La mortalidad materna en Nicaragua: una mirada rápida a los años 20002003. IPAS. Centro América.

${ }^{28}$ MINSA. Programa Nacional ITS/VIH/SIDA. 2005. Pautas de Tratamiento Antiretroviral.

${ }^{29}$ MINSA. 2006. Plan Estratégico Nacional de ITS/VIH/SIDA. Nicaragua 2006-2010.Managua, Nicaragua.
} 
several other responsibilities). Epidemiological surveillance is carried out in 45 sentinel sites ${ }^{30}$ and is passive in all other service delivery sites (i.e., only given to those who request it).

\section{OBJECTIVES}

The general objective of this project was to conduct a situation analysis of postpartum and postabortion contraception and PMTCT programs in Nicaragua. The study assessed the degree to which the programs had the resources necessary for their proper implementation, the factors that influenced their performance, and the resulting quality of care. Specifically, the project sought to answer the following questions:

- Do health institutions in Nicaragua have the resources available for providing family planning services during the perinatal period and during postabortion care?

- Do these services satisfy the contraceptive needs of women?

- Are Nicaraguan health institutions implementing any actions to prevent mother-to-child transmission of HIV?

- Do Nicaraguan institutions satisfy the contraceptive needs of women living with HIV?

\section{METHODOLOGY}

Data collection and analysis was commissioned to Alva, a Nicaraguan consulting firm that specializes in health research and had all the necessary contacts with the MOH. Alva was responsible for the study design, data collection, coding and entry, and analysis. Data collection took place from June to September 2006, data coding and data entry from September to November 2006.

\section{Quantitative component}

The quantitative component consisted of structured interviews with health providers and users, and service inventories in a sample of hospitals and health centers. The sample was designed to represent $\mathrm{MOH}$ health centers and hospitals at the national level and to quantify differences between sentinel and non-sentinel health centers. In addition, a sample of EMPs was selected to estimate differences between these services and those provided by the $\mathrm{MOH}$.

The sample of MOH establishments included 10 of the 17 SILAIS in the country. These SILAIS were selected to represent variations in terms of poverty, urbanization, HIV prevalence and health infrastructure. The sample followed a cluster design, in which SILAIS were grouped

${ }^{30}$ Dr. Reynaldo Aguilar, PAHO-Nicaragua. Personal interview. May 5, 2005. 
according to the proportion of the population living in extreme poverty, the percentage living in a rural community, the number of physicians per capita, and HIV prevalence. Within each of these clusters, researchers randomly selected one SILAIS (Boaco, Matagalpa, Chinandega, Estelí, Jinotega, Managua, Masaya, RAAN, RAAS and Rivas) (See Appendix 1 for a description of the SILAIS sampled).

In every SILAIS sampled, researchers chose an $\mathrm{MOH}$ hospital and two health centers (one sentinel health center and one non-sentinel center). The sample of hospitals was restricted to departmental hospitals because these are the only ones that offer obstetric care. Two hospitals were chosen in Managua: Hospital Alemán Nicaragüense and Hospital Bertha Calderón. The former serves as a departmental hospital and the latter was selected because its maternal and child health program serves as a national referral center. Health centers were chosen randomly. Sentinel health centers were selected from a list provided by the $\mathrm{MOH}$, which specified that the center had a PMTCT program. Non-sentinel centers were picked from all other centers that were not adjacent to a hospital. Overall, the sample of $\mathrm{MOH}$ hospitals and health centers covered 55 percent of the hospitals that offer obstetric care and 12 percent of the health centers in the country. In collaboration with the Nicaraguan Health Chamber, the research team selected, the three EMPs with the largest number of affiliates. These were Salud Integral and Hospital Militar in Managua, and AMOCSA in Chinandega. Appendix 2 lists the MOH hospitals, health centers and EMPs in the sample, according to the SILAIS where they are located.

Researchers stayed for one week in each health facility (in the case of MOH hospitals and EMPs, researchers also visited during the weekend). Several data collection instruments were used. For the EMPs and MOH hospitals, these included:

- Inventories of postpartum, postabortion and family planning services.

- Structured interviews with health providers, including hospital directors, Ob-Gyn directors, chief of nurses, and approximately 80 percent of health providers in the gynecological ward who serve during the three shifts.

- Structured interviews with approximately 80 percent of the women who received postpartum and postabortion care.

In the health centers (including those adjoining the MOH hospitals and EMPs in sample), the research team conducted the following activities:

- Inventories of antenatal and postpartum care and in family planning services.

- Structured interviews with all health providers involved in antenatal, postpartum and family planning services

- Structured interviews with all women who received antenatal care and with all women who had delivered in the last six months, independently of their reason for visiting the health center. 
Table 1 shows the number of observations according to the type of establishment and which services the health providers interviewed provided.

Table 1. Number of observations by type of instrument used and health facility

\begin{tabular}{|c|c|c|c|c|c|}
\hline \multirow{2}{*}{ Type of instrument } & \multicolumn{2}{|c|}{ Health center } & \multirow{2}{*}{ Hospital } & \multirow{2}{*}{ EMP } & \multirow{2}{*}{ Total } \\
\hline & Sentinel & Non-sentinel & & & \\
\hline Inventory & 10 & 9 & 11 & 3 & 33 \\
\hline Interviews with providers ${ }^{*}$ & 48 & 27 & 145 & 11 & 231 \\
\hline Antenatal care & 36 & 18 & -- & -- & 54 \\
\hline Postpartum care & 34 & 17 & 123 & 8 & 182 \\
\hline Postabortion care & -- & -- & 102 & 7 & 109 \\
\hline Family planning & 41 & 23 & 32 & 2 & 98 \\
\hline PMTCT & 33 & 20 & -- & -- & 53 \\
\hline Interviews with users & 277 & 236 & 952 & 249 & 1714 \\
\hline Antenatal care & 117 & 114 & 222 & 143 & 596 \\
\hline Postpartum care & -- & -- & 469 & 18 & 487 \\
\hline Postabortion care & -- & -- & 26 & 0 & 26 \\
\hline Six months postpartum & 160 & 122 & 235 & 88 & 605 \\
\hline
\end{tabular}

The sum of the number of interviews with providers according to the type of service provider is greater than the total number of interviews with providers, because some providers were involved in more than one service

In $\mathrm{MOH}$ hospitals and health centers, only five women refused the interview. In EMPs, 18 of the 161 women approached during antenatal care visits refused the interview. In addition, two women who had just delivered and two women in the six-month postpartum period refused their interviews. These cases are not included in Table 1.

Data were captured in EPI INFO and analyzed using Stata 8. Data were not weighted, so the results refer to the population interviewed. Given that researchers stayed in each establishment the same number of days and that they used the same criteria for selecting those who were interviewed, the sample is weighted by establishment size.

\section{Qualitative component}

The qualitative component had several purposes. The first was to determine users' perceptions of postpartum and postabortion family planning and of mother-to-child HIV transmission.

Researchers organized two focus group discussions with women who sought postpartum care in hospitals and health centers and two focus group discussions with women who had not received postpartum care.

The second was to assess the perceptions of reproductive health stakeholders. Researchers conducted in-depth interviews with $\mathrm{MOH}$ family planning, post-obstetric care, and PMTCT managers. They also conducted in-depth interviews with regional administrators of postpartum, postabortion and PMTCT programs in two SILAIS, and with experts and providers of reproductive health in NGOs and cooperating agencies, including NicaSalud, Profamilia, and the Nicaraguan Association of Persons Living with HIV (ASONVIHSIDA). 
To understand the perceptions and family planning needs of women living with HIV, researchers organized a focus group discussion with 13 women who are affiliated with ASONVIHSIDA. This is the largest association of its kind in Nicaragua and the only one that has affiliates in several municipalities. Participants came from four different municipalities. It is possible that, because they were affiliated with an NGO, the responses given by these women may have differed from responses given by women without a similar affiliation. However, because of the low HIV prevalence in the country, this was the only way to find a number of women living with HIV.

\section{Primary LeVel OF CARE}

\section{Services offered}

According to the service inventories, all health centers visited offered family planning, prenatal and postpartum care, vaccinations and child growth monitoring. 18 of the 19 centers where the inventories were completed offered FP counseling; 19 provided condoms and pills; 18 offered IUD insertions; 18 offered injectables; and one performed voluntary female sterilizations.

All the health centers visited indicated that they offered family planning counseling during antenatal care and claimed to have family planning counseling and methods available for women in the postpartum period. The schedule for family planning services and antenatal and postpartum care services was the same at all health centers. All centers gave individual family planning counseling. Six centers also gave counseling to couples in private offices. In addition, 10 health centers gave group talks to women in the waiting area. PMTCT counseling was offered in 18 centers and voluntary HIV testing was offered in 14 centers. In addition, Bluefields and Laguna de Perlas, located in two of the SILAIS with the highest HIV prevalence in the country, offered antiretroviral treatment, including prophylaxis for pregnant women.

\section{Resources for family planning services}

Knowledge and availability of national service delivery guidelines: The National Family Planning Guidelines were available in 15 of the 19 health centers. Other documents available included: Antenatal Care Guidelines, available in five health centers; the Manual for Reproductive Health, available in two health centers; and the Postpartum Care Guidelines, available in one health center. Four health centers did not have any of these documents.

Information, Education and Communication (IEC) materials: All health centers had family planning IEC materials and family planning flipcharts; 13 had brochures that women could take home, including some about the lactational amenorrhea method (LAM); six had DVDs or VHS materials and a DVD or VHS player; and two had slides. Seven centers reported having had stock-outs of LAM brochures during the last three months. 
Contraceptive methods: Stock-outs were a problem, especially in the case of injectables and IUDs. According to service inventories, 10 of the 19 centers where injectables were offered had run out of supplies in the three months prior to the study. At the time of the study, only one center did not have injectables available, but seven of the 18 centers that provided IUDs did not have the method or insertion kits. Pills were available in all centers and condoms in 16.

In all cases contraceptive supplies were kept in a dry and clean place and ordered according to expiration date. Inventories were updated frequently, as the last review had been within two months of our study, but they were not always precise: in four health centers the number of contraceptive methods found during the study was greater than that listed in the inventory.

Referral and counter-referral mechanisms: We asked providers what they did when a woman in antenatal care was interested in receiving a contraceptive method after delivery. Only four health centers gave a referral slip or indicated in the clinical record that the woman wanted to receive a contraceptive and the method she had chosen. The remaining 15 centers asked women to return after delivery. However, eight of these did not have a systematic mechanism to identify postpartum women and their contraceptive needs when they returned. Apparently these health centers trusted that women would return and that when they did, they would ask for their contraceptives themselves.

During the interviews with family planning providers, we asked what they did when a pregnant woman wanted to have sterilization performed. Only one in every four referred them to the hospital where they would give birth and these providers were clustered in 10 health centers, which suggests that in nine of the health centers visited, no provider made these referrals. Likewise, only 63 percent of the providers mentioned that they referred women in the interval period who wanted a female sterilization to the closest health unit where the procedure is performed, leaving four health centers with no one making these referrals.

Staff characteristics, capabilities and aptitudes: The functions of physicians in health centers are specialized, with only some physicians involved in family planning services in 16 of the 19 health centers. In the case of nurses and nurse auxiliaries this definition seems less clear, as in seven health centers all the nurses and nurse auxiliaries participate in family planning activities. Almost all the providers interviewed participate in antenatal and postpartum care, vaccination, and child monitoring.

Health providers were asked about their training on and knowledge of different family planning service delivery components. The most relevant results of these inquiries are:

- Almost all (95\%) health providers involved in family planning services have received some training on counseling or on contraceptive methods: $82 \%$ have received training on how to provide counseling and $78 \%$ on the advantages and disadvantages of contraceptive methods. The proportions that received training on the mode of action and on contraindications for postpartum women were lower (65\% and 63\%, respectively).

- Seven out of 10 of those providing family planning have been trained in IUD insertions (61\% of these have also been trained in postpartum insertions). Of the providers trained in IUD insertions, 22 percent said that they did not insert IUDs in the health center because the center 
did not have the proper conditions and IUDs were not part of the center's family planning program.

- Eighty-eight percent of health providers involved in postpartum care were aware of the effect of breastfeeding on postpartum amenorrhea.

- Two-thirds of family planning counseling providers knew the three LAM conditions. When asked to mention them, practically all $(95 \%)$ mentioned that the method involves exclusive or almost exclusive breastfeeding; three-quarters of providers mentioned that the baby needed to be younger than six months old, and two-thirds mentioned that the method is only effective if menses had not returned. The knowledge of these two conditions increased significantly among providers who had received training on the method ${ }^{31}$.

- Eighty-three percent of the providers who gave family planning counseling knew that combined hormonal contraceptives are contraindicated for breastfeeding women.

- Eight out of 10 health providers involved in postpartum care followed the most recent international recommendations ${ }^{32}$ regarding optimal birth spacing and advised women to wait at least two years before a new pregnancy, with 14 percent recommending a minimum wait of three years. However, $23 \%$ recommended waiting one year or less.

Record-keeping: Most health centers had a good record-keeping system for family planning services. All centers had a record of new family planning clients and the method they received, 17 had a record of the number of returning family planning clients; and 10 keep a record of the number of clients who received counseling (including postpartum clients).

\section{Resources for PMTCT services}

IEC Materials: Availability of IEC materials on PMTCT was limited. Of the 18 health centers that offer PMTCT counseling, six did not have any IEC materials; 10 had a flipchart and brochures; one had a VHS and a working player; and one had posters. Three health centers had VHS cassettes about HIV/AIDS but they did not have a player.

Staff characteristics, capabilities and aptitudes: PMTCT counseling relies primarily on physicians (55\%). Providers were asked to explain the main messages that they gave during PMTCT counseling. Eight of every $10(78 \%)$ said that they recommended an HIV test, and three of every $10(38 \%)$ suggested that women ask their partners to be tested. Risk factors and the possibility of mother-to-child transmission during pregnancy and breastfeeding were mentioned by 70 percent.

\footnotetext{
31 See Appendix 3 for a table showing providers' knowledge of LAM's conditions according to training received.

${ }^{32}$ With the "Three to five saves lives" motto, the last recommendation is to space births in three to five years. See Population Reports, Vol XXX, num 3 (https://www.infoforhealth.org/pr/113edsum.shtml).
} 
Providers were also asked if they gave family planning messages during their PMTCT counseling. Practically all of them $(94 \%)$ said that they did, although their messages focused on the condom. Eight out of 10 providers said that they told women that the condom is the only contraceptive method that protects them against HIV, and one third said that they advised HIV+ women to always use a condom, even if they also used another method. Staff from the health centers located in the SILAIS with the highest HIV prevalence (Bluefields, Corinto, Laguna de Perlas and Matagalpa) had received training on family planning for HIV+ clients. This training had not been replicated in health centers in areas with lower HIV prevalence.

Statistics and monitoring: Recordkeeping systems for PMTCT activities were still deficient in most health centers. Three-fourths (14) of all the centers that offered HIV testing during antenatal care kept a record of the number of clients that had an HIV test, but only eight had a record of the number of women who tested positive. Records of the number of women who received PMTCT counseling is even lower (six centers).

\section{Services provided}

\section{Services during antenatal care}

Family planning and breastfeeding: All

but 3 percent of the women interviewed during antenatal care wanted to wait at least two years before their next pregnancy, and 56 percent did not want to have any more children. When asked whether they were interested in using a contraceptive method after delivery, 96 percent said that they were, with most of them wanting to start its use in the first three months postpartum (46\% immediately after delivery, $22 \%$ at the $40^{\text {th }}$ day, and $18 \%$ at another time). When asked about their contraceptive preferences, 38 percent wanted to use injectables, 29 percent wanted female sterilization, and 17 percent wanted an IUD.

\section{Box 1. Lack of training and time are two obstacles to integrated antenatal care}

Lack of training and the pressure to perform multiple activities in a limited time were the two main obstacles to the PMTCT program identified during structured and indepth interviews with health providers involved in antenatal care and with two regional coordinators of the MOH's Women's Integral Care division.

Right before the data used in this study were gathered, staff from the MOH's central offices conducted regional trainings on PMTCT counseling. Nevertheless, this training left several questions unresolved. This is illustrated by a comment made by a provider in a health center on the border with a high HIV prevalence who had been trained recently:

\section{"We still have several questions about breastfeeding. I cannot go and talk to the users if I am not completely convinced because I still have several questions and concerns "a}

Shortage of time for PMTCT activities is exemplified in the words of an antenatal care health provider in Rivas:

"Another problem is that even when you have the resources and the willingness to give counseling, you have a lot of work because of the lack of staff. For instance, if I have ten minutes to be with a patient, it is very unlikely that I will give her good counseling. For example, if I am with a pregnant woman, I have to weigh her, take her blood pressure and conduct an examination; in addition to that, I have to tell her about breastfeeding, risk factors, PMTCT, offer her an HIV test. Plus, I have to see another 24 pregnant women. Because of the time factor you have to prioritize the messages you give."

${ }^{a}$ The original Spanish version is in Appendix 4 
Table 2 shows that about half of the women received information about family planning methods and where to obtain them, while approximately one third received information about the return of their fertility and one-fifth were told about $\mathrm{LAM}^{33}$.

Table 2. Family planning and fecundity information provided during antenatal care

\begin{tabular}{|l|c|}
\hline \multicolumn{1}{|c|}{ Information given } & $\begin{array}{c}\text { \% of women who have received the } \\
\text { information } \\
(\mathbf{n = 5 9 6 )}\end{array}$ \\
\hline Where to obtain a method & 51 \\
\hline Contraceptive methods & 48 \\
\hline Breastfeeding recommendations & 46 \\
\hline Return of fertility & 35 \\
\hline Their fertility intentions & 27 \\
\hline LAM & 21 \\
\hline
\end{tabular}

Source: Exit interviews with women in antenatal care

Only nine percent of the women who said they had received information on LAM were able to explain the three conditions of effective use of this method. Similar findings emerged with information about the return of fertility following delivery, as no more than 6 percent of the women who received information on this subject mentioned that it was linked to breastfeeding or the return of menstruation, and only 41 percent said that they could become pregnant within the first month of delivery. These results imply that the information they received was incomplete, not transmitted, or was not transmitted clearly.

Half of the women had received recommendations about breastfeeding, but most messages focused on the optimal duration of breastfeeding for at least six months. Only 38 percent of these women were told about early bonding (18\% of all women interviewed), and 11 percent were told how to solve problems they may have during breastfeeding.

PMTCT: Even though all but one of the health centers visited said that they gave PMTCT counseling during antenatal care, only 27 percent of the women interviewed declared having heard of HIV during their visits. This percentage did not increase for women who had more than one visit ${ }^{34}$, but interestingly, it was greater among women attending non-sentinel sites than among those attending sentinel sites $(34 \% \text { vs. } 21 \%)^{35}$.

\footnotetext{
33 These results are slightly higher for women who have attended two or more antenatal care visits. For example, $53 \%$ of the women who have attended two visits and $51 \%$ of the women who have attended three or more visits have received information on the contraceptive methods. For the sake of simplicity we present the results for the general population here.

${ }^{34}$ See Appendix 6 for a table showing the percentage of women who have received HIV information during antenatal care by number of ANC visits.

${ }^{35}$ This difference is significant with $\mathrm{p}=0.034$ (see Appendix 7).
} 
The topic women most often recalled from counseling was risk factors for infection (75\%). Six out of 10 women said that they had been told that using a condom reduces the risk of infection and a similar proportion mentioned that HIV can be transmitted from mother to child during pregnancy, delivery or breastfeeding. Only 38 percent of women mentioned that providers had recommended during counseling that they take an HIV test.

Three-quarters of women who did not receive HIV information during antenatal care had obtained information elsewhere. What these women remembered about HIV was very similar to what was remembered by those who received PMTCT counseling: the risk factors ( $84 \%)$; that condom reduces the risk of infection (72\%) and that the virus can be transmitted from mother to child (61\%).

Eight out of 10 women had had a blood test during their antenatal care visit. We did not ask women if these included

HIV testing because during the pilot phase of the study we discovered that this was still a very sensitive subject in Nicaragua. Women would not answer questions as to whether they had been tested for HIV, or they would say that they did not know ${ }^{36}$. However, eight percent of the women sampled spontaneously mentioned that they had had a blood test but did not know what they had been tested for.

\section{Services during the first six months postpartum}

These results are based on 602 respondents who had had a delivery in the previous six months. Almost half of these women (46\%) were seeking curative care for their babies or for themselves; 40 percent brought their babies for vaccination or a child monitoring visit; 8 percent were seeking family planning counseling; and 5 percent a postpartum check-up. Since the sample was not limited to women who were in the health center for a postpartum checkup or for well-baby care and immunization services, the questions about the information and services that they had received during this visits were retrospective. Practically all women in the sample $(96 \%)$ had attended at least one postpartum checkup (74\%) or one vaccination or well-baby care visit

36 The fact that 63 percent of the women interviewed do not think that they are at risk of being infected attests to this sensitivity. 
(94\%). The main reasons for not attending a postpartum visit were that women did not consider it important (22\%), did not know they had to go (20\%), or did not have time (20\%).

Family planning services: Four out of 10 women interviewed received family planning counseling during their postpartum visits to the health center, and a similar percentage (39\%) were asked if they would like to use a contraceptive method. One of every five women (19\%) received a contraceptive method when they were in the hospital for delivery. Of those that did not receive a method in the hospital, 44 percent received a method during their postpartum visits, which means that 55 percent of women had started contraceptive use at the time of the interview $^{37}$.

Women who received a contraceptive method during their postpartum visits were mainly using injectables (59\%), pills (17\%), female sterilization (10\%), and condoms (8\%). Contrary to the WHO recommendation ${ }^{38}$ to postpone the use of hormonal contraceptives for at least six weeks after delivery, especially in the case of breastfeeding women, at least 20 percent of the pill and injectable users began using these methods before the end of the first month postpartum. All of these women were breastfeeding when they started contraceptive use ${ }^{39}$.

All but four women (less than 1\%) who were not using a contraceptive method in the six-months postpartum period wanted to avoid or delay their next pregnancy for at least two years, and 82 percent wanted to use a contraceptive method in the following six months, with 14 percent declaring that they would like to start using a method immediately and 48 percent saying that they would like to start use within the next three months ${ }^{40}$.

37 See Appendix 8 for a distribution of women in the six months postpartum according to their adoption and willingness to use a contraceptive method.

38 WHO: 2004. Medical Eligibility Criteria for Contraceptive Use (Third Edition). WHO, Geneva.

39 The National Family Planning Guidelines that were current in Nicaragua at the time of the survey mentioned that progestin-only hormonals could be used immediately after delivery.

40 See Appendix 8 


\section{Box 3. Injectable contraceptives are one of the most popular methods among postpartum women, but their use is hampered by the lack of information}

Interviews with pregnant women, women who just gave birth, and women in the six-month postpartum period show that injectables are one of the most popular contraceptive methods. Four out of 10 pregnant women said that they would like to use this method after delivery and 43 percent of those who left the hospital with a contraceptive were using injectables. Their popularity seems to increase with time since delivery: six of every 10 women using a method in the six-month postpartum period were on injectables, and it was the preferred method of 55 percent of those who are not using any method.

Despite their popularity, the use of injectables is affected by a lack of clarity in the instructions that providers give to women. Providers who know of the method's contraindications during postpartum often do not clearly explain their reasons for delaying delivery of the method and do not make it clear when women should come back. During the interviews with women in the six-month postpartum period, only 14 percent of women who wanted injectables cited the provider's instruction to wait as a reason why they were not yet using this method.

Focus group discussions with postpartum women illustrate the lack of information and obstacles that women face when they want to use injectable contraceptives. Several respondents in a rural health center mentioned that they wanted to use injectable contraceptives; nurses said that they could only get the injection when they were menstruating. The experience of a woman who had still not received the method five months post-delivery shows that this measure can be arbitrary, especially in the case of breastfeeding women:

"The first time I came my baby was three months old and my husband was [away], but they did not want to give me the injection. They told me that I should come back while menstruating. I answered that my husband was not with me. I told her:' My husband is in another country and I have not had sexual relations, please give it to me.' 'No!' they told me, and it is until now that I have come back." a Other women explained that they had had to switch contraceptive methods because of injectable stockouts. An example of this is a woman that gave birth at home with the aid of a midwife and that we interviewed in Ciudad Sandino. Following her birth attendant's recommendation, Laura went to her closest health post eight days after delivery. There, providers explained that she could use one- and three-month injectables, pills and IUDs. She chose the one-month injectables and got her first injection. When she returned for her second application, the health post had run out of injectables and she had to stop using the method. Two months afterwards, she came back to the health post and asked for pills, which she was still using when we interviewed her.

${ }^{\text {a }}$ The original Spanish-language version is in Appendix 9

Among women in the six-month postpartum period, 16 percent were at risk of an unplanned pregnancy because they were not using a contraceptive method and had stopped exclusive breastfeeding, or because their menses had returned (see Figure 1). These women represent 35 percent of those who were not using a method, which, if compared to the 14 percent who wanted to start using contraception immediately, implies that many women who are at risk do not know it yet. 
Figure 1. Exposure to an unplanned pregnancy among women in the six-month postpartum period (5)

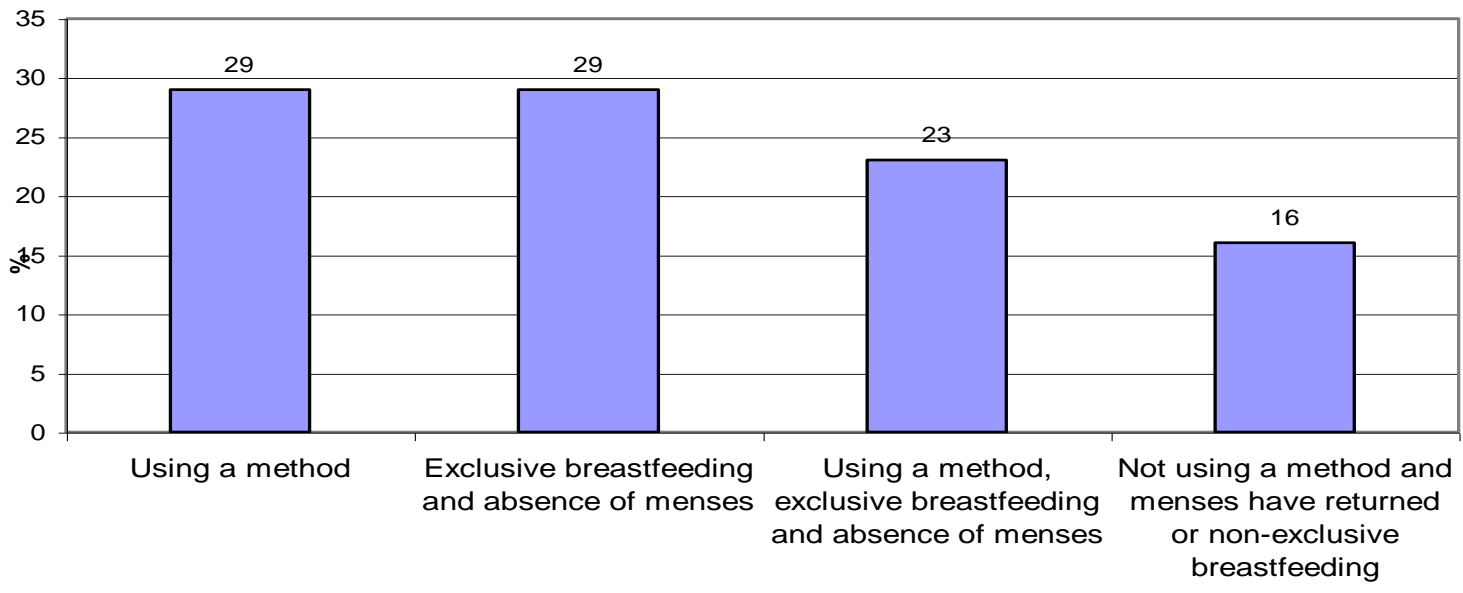

Four groups of women who were particularly exposed to the risk of an unplanned pregnancy in the six months postpartum were those who live in rural areas, women who spoke Miskito, women who were in non-stable relationships (single, widowed, and divorced) and women who had less than three children ${ }^{41}$.

Referral for other services: Only 10 percent of women had been asked during their visit to the health center if they wanted to receive another health service. However, when we asked women whether they would have liked to receive or be referred to other services, several health needs were detected: 8 percent said that they needed a postpartum check-up; 22 percent family planning counseling; 21 percent a pap smear; 17 percent HIV counseling and testing; 9 percent counseling on how to prevent or deal with domestic violence; and 13 percent curative services.

\footnotetext{
${ }^{41}$ Appendix 10 shows the percentage of each of these groups of women who are exposed to the risk of an unplanned pregnancy.
} 


\section{Box 4. Family planning counseling during a hospital stay for delivery and during post-delivery maternal and child-visits increases contraceptive use in the six months postpartum}

Using data from the interviews with women in the six months postpartum, we explored whether the timing of family planning counseling (during antenatal care, during the hospital stay for delivery, and during post-delivery maternal and child health visits) increased the odds of using a contraceptive method. Analytical methods used included grouping women according to the services they received (women who received antenatal care and delivered in a hospital; women who had a hospital delivery but did not attend antenatal care; and women who did not receive antenatal care or had a hospital delivery) and doing cross-tabulation analysis according to the timing of family planning counseling. Researchers also conducted logistic analysis that controlled for age, marital status, parity education, exclusive breastfeeding, resumption of menstruation, attendance at antenatal care, and institutional delivery ${ }^{\mathrm{a}}$. The most relevant findings were:

- The proportion of women using contraception in the six months after delivery was greater among women who received antenatal care than among women who did not (15\% vs. $4 \%)$. However, among women who attended antenatal care, family planning counseling during these visits did not significantly affect postpartum contraceptive use (the percentage of users was $15 \%$ in both cases)

- Giving birth in a hospital did not significantly increase the odds of using a contraceptive method

- Controlling for hospital delivery and all other factors, receiving family planning counseling before hospital discharge increased the odds of contraceptive use by 73 percent

- Once attendance to antenatal care, hospital delivery, family planning counseling at each of these occasions, and socio-demographic factors had been controlled for, women who received counseling during post-delivery visits were 98 percent more likely to use a contraceptive method than women who did not receive counseling during these visits.

\section{${ }^{a}$ The results of this analysis can be found in Appendix 11}

\section{SECONDARY LEVEL OF CARE}

\section{Services offered}

Inventories in $11 \mathrm{MOH}$ hospitals and three EMPs showed that all the establishments visited offered family planning counseling to postpartum and postabortion women before hospital discharge; all establishments but one EMP offered contraceptive methods to postpartum women; and nine hospitals offered contraceptive methods to postabortion women. The methods offered varied among establishments and were particularly limited in EMPs (see Table 3). 
Table 3. Contraceptive methods offered to postpartum and postabortion women before hospital discharge, by type of establishment (number of women)

\begin{tabular}{|l|c|c|c|c|}
\hline \multirow{2}{*}{ Method } & \multicolumn{2}{c|}{ MOH hospitals (n=11) } & \multicolumn{2}{c|}{ EMPs (n=3) } \\
\cline { 2 - 5 } & Postpartum & Postabortion & Postpartum & Postabortion \\
\hline Injectables & 9 & 9 & 1 & 0 \\
\hline IUDs & 10 & 8 & 0 & 0 \\
\hline Pills & 7 & 7 & 0 & 0 \\
\hline Female sterilization & 9 & 6 & 1 & 0 \\
\hline Condoms & 7 & 6 & 0 & 0 \\
\hline LAM counseling & 5 & n.a. & 0 & n.a. \\
\hline
\end{tabular}

Source: Service inventories in hospitals and EMPs

Even though all $\mathrm{MOH}$ hospitals that delivered contraceptive methods to postpartum and postabortion women mentioned that the methods were given in the Ob-Gyn ward, four hospitals delivered methods only five days per week.

At the time the study was conducted, $\mathrm{MOH}$ hospitals were responsible for designing and implementing their own PMTCT activities. As a result, there were variations between establishments. Of the $11 \mathrm{MOH}$ visited, seven performed caesarean sections for HIV+ women; four counseled women on substitute formula nutrition and offered free breast milk substitutes; four gave the mother antiretrovirals during labor and delivery; and three offered antiretrovirals to the baby after birth. The two hospitals that had the most complete PMTCT program (offering all four services) were the Hospital Bertha Calderón and the Hospital Mauricio Abdalah, which served as the national referral centers for HIV+ women's deliveries. In addition, eight $\mathrm{MOH}$ hospitals had HIV tests available for postpartum and postabortion women.

\section{Resources for family planning services}

Knowledge and availability of national service delivery guidelines: In seven of the $11 \mathrm{MOH}$ hospitals providers had a copy of the post-obstetric contraception guidelines available (six had the National Family Planning Service Delivery Guidelines and one had the National Delivery and Postpartum Care Guidelines). Of the three EMPs, only one had the National Family Planning Guidelines or service delivery guidelines available.

IEC materials: In 10 of the $11 \mathrm{MOH}$ hospitals there was at least one poster or announcement informing clients that family planning services were available. With the exception of one hospital, all had some kind of IEC material that could be used during family planning counseling. Most commonly, these materials were brochures (in 9 hospitals) and flipcharts (in 7 hospitals). In five hospitals the research team also found posters explaining the different contraceptive options; and five hospitals had brochures about LAM. Audiovisual materials were seldom used, as only one hospital had videocassettes with family planning-related programs; and one hospital had slides. Postpartum and postabortion IEC materials were found in six hospitals. 
EMPs lacked IEC materials on family planning and on postpartum and postabortion care, including the most basic (flipcharts and brochures). None of the EMPs had visible announcements about available family planning services.

Contraceptive methods: Few $\mathrm{MOH}$ hospitals admitted during the service inventories that they had suffered stock-outs during the last three months ${ }^{42}$. However, on the day of the visit researchers corroborated the physical availability of methods in only a few hospitals. IUDs and injectables were available in only one hospital each; and condoms in two. Female sterilization and oral contraceptives (both minipills and combined pills) were the two methods most readily available (in six and five hospitals, respectively). The one EMP that offered injectables did not have the method available on the day of the visit.

All but one $\mathrm{MOH}$ hospital kept written inventories of their contraceptive supplies, and all of them were up to date. However, in eight of the 11 hospitals visited, contraceptives were not kept properly (they were not stocked according to the expiration date or protected from sunlight).

Referral mechanisms: MOH hospitals and EMPs need a mechanism to identify those postpartum women who want to receive a contraceptive method before discharge, especially IUDs and female sterilization, methods that can be provided immediately after delivery or postplacenta. The clinical histories that women bring with them to the hospital do not specify whether they want to receive a method after delivery or which method they want to receive. During the service inventories, the research team asked what was done if postpartum and postabortion women wanted to receive a contraceptive method after hospital discharge. In all cases the response was that they gave a written referral. All EMPs specify the date where women should return.

Staff characteristics, capabilities and attitudes: In all hospitals visited (except for the one EMP that did not offer family planning services) all health providers involved in postpartum care were also involved in family planning. In the case of postabortion care, not all PAC nurse and nurse auxiliaries were involved in family planning. Seven out of 10 providers who give family planning counseling $(68 \%)$ had at some point been trained on counseling for both postpartum and postabortion women.

Of the providers that delivered contraceptive methods, 90 percent had been trained in the delivery of at least one method: 39 percent on female sterilization and 73 percent on postpartum and postabortion IUD insertions. All $\mathrm{MOH}$ hospitals have at least one provider who has received training to perform female sterilizations.

Almost half (44\%) of the providers that had been trained on postpartum and postabortion IUD insertions did not deliver the method. When asked why, 44 percent (these were nurses) said that only the physicians inserted IUDs; 22 percent said that it was not in their job-description; and 11 percent said that IUD insertions were not covered in the hospital service delivery guidelines.

${ }^{42}$ One hospital said that they had run out of minipills; three mentioned condom stock-outs; two injectables and one LAM brochures. 
Similar barriers were found for postpartum female sterilization, but in this case related to the perception that they are the exclusive domain of obstetric-gynecologists. Of the 38 providers trained in female sterilization, 13 (34\%) did not perform the procedure. When asked why, six said that these were the responsibility of specialists and two that the hospital did not have a program for this.

Interviews with providers also explored their knowledge about the return of fertility in postpartum and postabortion women. Important knowledge gaps were detected: only 15 percent of the providers said that the return of fertility in postpartum women was associated with breastfeeding or the return of menses. The rest responded with specific times - such as immediately after childbirth or in the first month postpartum $(52 \%)$ or at six months (9\%). Also, 40 percent did not know that LAM depends on the baby's age and the absence of menstruation. In the case of PAC, only half of the providers (49\%) knew that the return of fertility can occur in the first 15 days. One-third (34\%) said that they did not know, and 17 percent said that fertility returned after one month. Although the National Family Planning Guidelines mentions that combined hormonal contraceptives should not be used while breastfeeding, 23 percent of providers did not know any contraindication for their use during lactation.

Record-keeping: One of the MOH's strategies to improve post-obstetric family planning is to keep service statistics on the number of postpartum and postabortion women who leave the hospital with a contraceptive method. All the MOH hospitals visited kept such records for postpartum women, but in two hospitals they only recorded female sterilizations. For postabortion care, 10 of the $11 \mathrm{MOH}$ hospitals kept a record of the number of clients (using Ipas's InfoAPA and EvalAPA systems). However, only seven hospitals recorded how many of these clients received a contraceptive method and only five specified the method delivered. Two of the three EMPs kept a record of postpartum and postabortion clients, but they did not specify how many received a contraceptive method.

\section{Box 5. Coordination between the MOH's central and local levels is necessary to have a working monitoring and evaluation strategy}

All the key informants interviewed during the qualitative component of this study agreed that the $\mathrm{MOH}$ needs to develop monitoring and evaluation (M \& E) mechanisms to track the program's effectiveness and to enforce providers' adherence to national guidelines. The Health Care Improvement Project has been working with the $\mathrm{MOH}$ to develop a record-keeping system to track the number of postpartum and postabortion women who leave with counseling and a method in all its hospitals. However, during our interviews we detected that $\mathrm{MOH}$ staff, both at the local and at the central level, were not clear about how these statistics are used or who analyzes them. An interviewee at the central level said that M \& $\mathrm{E}$ was the responsibility of local-level providers, and that the role at the central level was to give technical assistance and make periodic visits. However, interviewees at the SILAIS explained that at the local level they only compiled the statistics and sent them to the central-level $\mathrm{MOH}$. In addition, a Health Care Improvement representative said that the central $\mathrm{MOH}$ offices were not doing a perfect job at integrating all the statistics and that this information sometimes got lost. 


\section{Resources for PMTCT}

Knowledge and availability of guidelines: None of the hospitals or EMPs visited knew of any guidelines regarding the prevention of mother-to-child transmission of HIV.

IEC materials: IEC materials about HIV were only available in eight MOH hospitals. EMPs did not have any HIV materials.

Antiretrovirals: Of the three hospitals that said they offered antiretrovirals for women who are delivering and for their babies, only one had a written inventory of its antiretrovirals. In the three hospitals, supplies were stocked in an orderly manner and kept in a dry, dark place.

Staff characteristics, capabilities and aptitudes: Providers who give family planning counseling were asked whether they gave counseling to women living with HIV and whether they gave any special messages in those cases. Eight providers in the two referral hospitals for HIV+ women said they did. The messages that they emphasized were the use of condoms as a dual protection strategy, to be faithful to their partner, and not to breastfeed or use LAM.

\subsection{Services during hospital stay for delivery}

This section is based on exit interviews with 467 women who delivered at MOH hospitals and 18 women who delivered at EMPs. Sixty-two percent of these women did not want to have more children in the future, and with the exception of 11 women, all of them wanted to wait at least three years before their next pregnancy.

Early bonding: $\mathrm{MOH}$ hospitals promoted early bonding between mothers and children. Seventy-eight of the women who gave birth in these establishments had their babies with them most of the time they stayed in the hospital. Also, 60 percent nursed almost immediately after delivery and 72 percent nursed in the first two hours. EMPs placed less emphasis on early bonding than MOH hospitals: only 47 percent of women had their babies in the same room; 35 percent nursed immediately after delivery and 40 percent nursed in the first two hours.

Postpartum family counseling, breastfeeding and optimal-birth spacing information: Table 4 shows the percentage of women who said that they received family planning counseling, were offered a contraceptive method, and received information about the return of fertility and breastfeeding before hospital discharge according to the type of hospital where they gave birth. 
Table 4. Percentage of women who received information about different family planningrelated topics before hospital discharge, by type of hospital

\begin{tabular}{|l|c|c|}
\hline \multicolumn{1}{|c|}{ Type of information } & $\begin{array}{c}\text { MOH hospitals } \\
(\mathbf{n}=467)\end{array}$ & $\begin{array}{c}\text { EMPs } \\
(\mathbf{n}=18)\end{array}$ \\
\hline Return of fertility & 32 & 35 \\
\hline $\begin{array}{l}\text { Return of fertility is linked to } \\
\text { breastfeeding and/or menses } \\
\text { return }\end{array}$ & 5 & 0 \\
\hline Optimal birth spacing & 48 & 29 \\
\hline Family planning counseling & 64 & 29 \\
\hline Offered a contraceptive method & 73 & 47 \\
\hline Breastfeeding & 76 & 35 \\
\hline
\end{tabular}

Source: Exit interviews with women who delivered in MOH hospitals and EMPs

The following results are observed in this table:

- Three-quarters of women who delivered in $\mathrm{MOH}$ hospitals received information about breastfeeding (how to breastfeed, how to solve breastfeeding problems and how long to breastfeed), and were offered a family planning method. Also, six of every 10 received family planning counseling before hospital discharge.

- Only one third women who delivered in $\mathrm{MOH}$ hospitals remembered being told about the return of their fertility. When asked when they would be at risk of becoming pregnant again if they did not use a contraceptive, 5 percent gave an answer related to breastfeeding or the return of menstruation. The rest answered that the risk began immediately (8\%), on the $40^{\text {th }}$ day after delivery (14\%); between the second and sixth month after delivery (30\%); after the sixth month after delivery (20\%); or that they did not know (20\%).

- Women who delivered in EMPs were less likely to receive information on family planning, breastfeeding, and optimal birth spacing than women who delivered in MOH hospitals.

Contraceptive methods: Four out of 10 women (44\%) who delivered in a MOH hospital received a contraceptive method ${ }^{43}$. Of those who did not receive one, half $(52 \%)$ would have liked to receive a contraceptive method before hospital discharge. When these women were asked why they did not obtain a method, 82 percent said that it was because they were not offered one. In EMPs, the percentage of women who received a contraceptive method before discharge was 35 percent.

Having at least one nurse on the maternity unit who provided family planning services and offered an array of different contraceptive methods increased the probability that women would leave the hospital with a contraceptive (see Figure 2).

\footnotetext{
${ }^{43}$ This percentage matches that of post-obstetric event contraception reported by the MOH in the year 2004 (source: Estadísticas de servicio del MINSA).
} 
Figure 2. Women who wanted and received a contraceptive method before hospital discharge for delivery, according to hospital characteristics $(\%)^{*}$

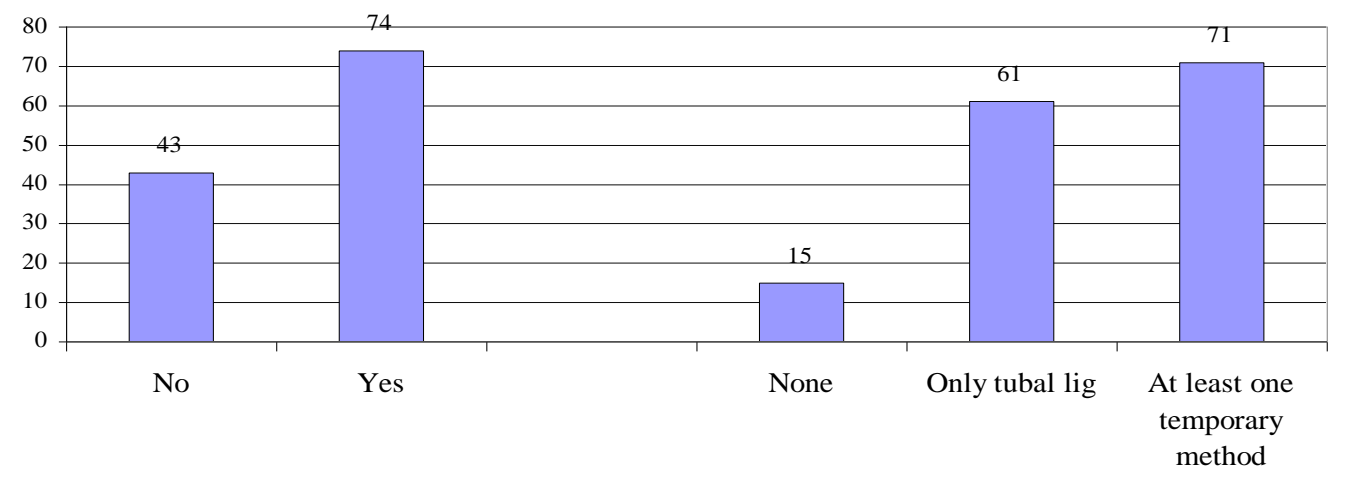

* Sample sizes were as follows: No nurses $(n=166)$, at least one nurse $(n=189)$; no methods $(n=58)$; only tubal ligation ( $\mathrm{n}=69)$; at least one temporary method $(\mathrm{n}=228)$

Source: Exit interviews with women who delivered in MOH hospitals and EMPs

Factors that reduced the probability of receiving a method before hospital discharge, even after controlling for the desire to use a method, were giving birth in an urban department, being under 20 years old, being more educated, and having 2 children or less ${ }^{44,45}$

Four out of 10 women who received a contraceptive method before hospital discharge for delivery got an injectable. The other methods most commonly obtained were female sterilization $(35 \%)$ and IUDs (13\%). Method preference was significantly associated with parity and age, with younger women and those with less than three children opting for temporary methods, and older and higher-parity women choosing female sterilization ${ }^{46}$.

Most of the women who received a contraceptive method before hospital discharge were told when and where to go for resupply, and in the case of the IUD, where to go for a check-up. However, few women received information about side effects, what to do in case of a complication, and, with the exception of female sterilization, method reversibility (see Table 5). Only 53 percent of the women who did not receive a contraceptive before hospital discharge were referred to a place where they could obtain a method afterwards. Most of these referrals $(61 \%)$ were made verbally and women did not receive any written indications.

\footnotetext{
${ }^{44}$ These results hold for the probability of receiving family planning counseling as well.

45 More information about these results can be found in Appendix 12, which contains cross tabulations of the percentage of women who received family planning counseling and who wanted and received a contraceptive method for each of these variables.

${ }^{46}$ See Appendix 13.
} 
Table 5. Information about contraceptive methods received before hospital discharge from delivery, according to method received (\%)

\begin{tabular}{|l|c|c|c|}
\hline \multicolumn{1}{|c|}{ Type of information } & $\begin{array}{c}\text { IUD } \\
(\mathrm{n}=25)\end{array}$ & $\begin{array}{c}\text { Injectables } \\
(\mathrm{n}=84)\end{array}$ & $\begin{array}{c}\text { Tubal ligations } \\
(\mathrm{n}=69)\end{array}$ \\
\hline When and where to resupply & 80 & 93 & $\mathrm{n} . \mathrm{a}$. \\
\hline Side effects & 20 & 35 & 26 \\
\hline Reversibility & 28 & 0 & 75 \\
\hline What to do in case of complications & 16 & n.a. & n.a. \\
\hline
\end{tabular}

Source: Exit interviews with women who delivered in MOH hospital and EMPs

\section{Services provided during postabortion care (PAC)}

This section is based on exit interviews with 26 women who received postabortion care (PAC) in $\mathrm{MOH}$ hospitals. During the week that the research team visited EMPs, there were no PAC cases.

Three-quarters of women were seen by a health provider within the first 30 minutes of arriving at the hospital. The rest had to wait between one and two hours, and one woman mentioned that she had waited more than 10 hours.

Six out of 10 women who received PAC in MOH hospitals said they did not receive family planning counseling before they left. Similar proportions of women said they had not received information on the return of fertility after the treatment and had not been asked whether they wanted to use a contraceptive method (see Table 6). 
Table 6. Family planning-related information received before hospital discharge from postabortion care

\begin{tabular}{|l|c|}
\hline \multicolumn{1}{|c|}{ Type of information } & $\begin{array}{c}\text { Women who received information } \\
(\mathbf{n = 2 6 )}\end{array}$ \\
\hline Family planning counseling & 39 \\
\hline Were offered a contraceptive method & 39 \\
\hline Return of fertility & 35 \\
\hline Were asked about their fertility plans & 23 \\
\hline Correct information on the return of fertility & 12 \\
\hline
\end{tabular}

Source: Exit interviews with postabortion women in $\mathrm{MOH}$ hospitals

Of the nine women who remembered being told about the return of fertility after treatment, three were able to explain that they were at risk of becoming pregnant again within the first month, four women mentioned a longer period, and two did not know.

When asked which methods had been discussed with them, eight of the 10 women who received counseling mentioned injectables, six mentioned oral contraceptives, and four mentioned condoms, IUD and female sterilization. The methods discussed did not depend on the methods available at the hospital.

One-third of women (31\%) left the hospital with a contraceptive method. Of eight women who received a method, six got injectables, one an IUD, and one sterilization. All of them received information about where to obtain the method in the following months. However, these women did not receive clear information about the risks and side effects of the methods they chose. When asked what they had been told about their method (first answering spontaneously and then with help), none of the women who obtained injectables remembered being told that the injectables can cause irregular periods or inter-period spotting. Similarly, the woman who received the IUD remembered that

\section{Box 6. Postabortion women want to postpone their next pregnancy for more than two years, independently of whether their pregnancy was planned or not}

At least one-fifth of the women receiving PAC (27\%) had experienced a planned pregnancy, and were not using a contraceptive method because they wanted to become pregnant. However, after their miscarriage, all of them changed their minds and said they wanted to wait at least a year before a new pregnancy. Only one of the seven women in this situation received a family planning method before hospital discharge, and all the others wanted to start contraceptive use in the following month.

One-third of all PAC women (35\%) were using a contraceptive method when they became pregnant. Another one-third (38\%) were not using a method because their partners opposed it, they did not know where to obtain one, or they were afraid of their side effects. All these women wanted to postpone their next pregnancy for at least one year or did not want to have more children.

she had been told about how to check that the IUD was in place, but not that the method could cause cramping and increased bleeding, or what symptoms could indicate that there were complications and that she needed to go back to the doctor. 
Of the 22 women who did not receive a contraceptive method before hospital discharge, 13 would have liked to receive one, five wanted to start using a method in the following two months, and four did not know when they would like to start use. When women who wanted to receive a method and had not gotten one were asked why they had not received it, they answered that they had not been offered one (64\%), hospital staff had asked them to wait (18\%) or the method they wanted was not available (9\%).

Only two of the 18 women who did not receive a contraceptive before discharge but wanted to use one in the first two months postabortion received a referral for family planning services. Even though all these women said that they knew where to obtain a method, not receiving a referral could decrease their chances of obtaining the method they wanted and needed.

\section{PMTCT AND FAMILY PLANNING NEEDS OF WOMEN LIVING WITH HIV}

This section summarizes the findings of a focus group discussion with 13 women who were living with HIV/AIDS and were associated to ASONVIHSIDA, the largest organization of its kind in Nicaragua. Women in this session came from different SILAIS, including Chinandega, Leon, Managua and Matagalpa. Most of the women in the group (10) discovered that they were HIV+ because they were tested after their husbands started showing symptoms. Other women found out about their status through tests during antenatal care, but in some cases the waiting period between the test and the result was long:

"Well, I knew that I was HIV+ because my husband suffered an accident while working. They started giving him some tests and, because he had a few symptoms, they asked him whether he wanted to be tested for HIV. He was in bed and then I realized that he was HIV+. I was pregnant at the time and I got tested and I got my results at the fourth month."

"I was in my first month when I realized that he was HIV+ and I got tested. I did not get my results until the fourth month."

After being diagnosed, these women were referred to the Hospital Mauricio Abdalah, where they have been receiving all their health care. They usually see the same doctors, with whom they discuss any concerns they have, from headaches to health and lifestyles. Among the recommendations that they receive are that they eat well, and that they do not drink, smoke, or suffer from sleep deprivation.

In addition, all the women in the group mentioned that during their visits to the hospital they are consistently reminded that they should use a condom. Comments by respondents suggest that condoms are mentioned as a dual-protection strategy and that health providers in the hospital sometimes discourage the use of other contraceptive methods. When asked what

${ }^{47}$ Original Spanish verbatims can be found in Appendix 14. 
recommendations they received regarding family planning and reproductive health, women mentioned:

"No, we don't get a treatment or anything. No one in the hospital uses a contraceptive. We use the condom; we don't use any other kind of family planning."

"We used family planning before we were diagnosed with HIV. After our diagnosis, we were told that we should use the condom to prevent mutual re-infection. We are not told to use other contraceptive methods. We use the male or the female condom, or we don't use anything else. Before being diagnosed I used other methods."

"The doctor told me that I should not use any other method, that if I used the pill my partner and I could be constantly re-infecting each other. Then she told me that no other method was of use, and that is why I use the condom. Still, I do not feel confident. There is the risk that the condom will break."

The group shared a feeling that condoms were not completely effective as a contraceptive indeed, one woman had become pregnant while using this method. Despite this feeling, all but two of the women in the group were currently using condoms and nothing else (one woman was also using injectables and one had had a voluntary sterilization). Furthermore, some women had discontinued use of the contraceptives they were using before following their doctors' instructions:

"In my case, I asked when I was diagnosed what method I could use and I was told to use the condom. I asked whether I could continue using the pills or injectables and I was told that it was unnecessary, that if I was using the condom, why should I use another method?" 


\section{CONCLUSIONS AND RECOMMENDATIONS}

This report presents the findings of a situation analysis of contraceptive services in postpartum, postabortion, and PMTCT programs in Nicaragua. The results show that there are many strengths in these services, but also many opportunities for improving quality of care, particularly for all services in the EMPs, in the provision of postpartum and postabortion services in $\mathrm{MOH}$ hospitals, and in the delivery of family planning services to women living with HIV.

The MOH was consulted throughout the design and implementation of the project, and the findings were discussed with them on several occasions. The report emphasizes some analyses that the $\mathrm{MOH}$ had requested during these meetings. Final results were presented to $\mathrm{MOH}$ directors and local $\mathrm{MOH}$ administrators, and have been used to formulate the workplan for the administration that took over in 2007.

The project results were also presented to the HealthCare Improvement project and NicaSalud representatives during a regional workshop in October 2007, at which several of the recommendations presented below were discussed. At the end of the workshop these representatives agreed to work together to follow up with national and local authorities and other cooperating agencies, and use these results as inputs for a plan to improve postabortion, postpartum and PMTCT services.

Based on the findings of this study, we propose the following strategies to improve the linkage of family planning services and postpartum and postabortion services:

a) Increase the role of nurses and nurse auxiliaries in maternity and Ob-Gyn wards in the delivery of family planning counseling and contraceptive methods. The study showed that women who delivered in a hospital where at least one nurse in the maternity ward provided family planning services were more likely to receive a contraceptive before hospital discharge. It also showed that, in many cases, doctors assumed that nurses were responsible for providing family planning counseling to postpartum and postabortion women. Making family planning counseling a routine part of nurses' rounds with postpartum and postabortion women may result in an increased percentage of users receiving counseling before hospital discharge.

b) Conduct refresher training for all staff involved in family planning, postpartum and postabortion care. This training should pay special attention to explaining which methods are contraindicated for postpartum women (breastfeeding and non-breastfeeding), how long after an abortion postpartum and postabortion women regain their fertility, and the role of breastfeeding and amenorrhea in postpartum infertility. The promotion of the new National Planning Guidelines (to be published later this year) may be a good opportunity for such training.

c) Develop or adapt IEC materials, including checklists, which remind health providers of the family planning methods recommended for postpartum and postabortion women, and of other information that they should give pregnant and postpartum women 
during their visits. Adoption of the Balanced Counseling Strategy ${ }^{48}$ developed by FRONTIERS may serve to remind health providers of the eligibility criteria for different contraceptive methods.

d) Organize workshops to renew interest in postpartum and postabortion IUDs and to promote participation of trained staff. Service inventories show that there is the demand for this method among postpartum women, and that hospitals and health centers have trained staff who could be conducting insertions but are not doing so.

e) Improve the referral mechanisms between establishments at the primary and secondary level of care. Clinical histories can be used to indicate whether a woman wants to receive a contraceptive method immediately after delivery (especially in the case of IUDs and tubal ligations). Also, postpartum and postabortion women who want to receive a contraceptive method in the future should obtain a written referral with clear indications of when and where to obtain the method.

f) Develop a mechanism to identify women with an unmet need for family planning during their post-delivery maternal and child visits. An adaptation of the Systematic Screening technique developed by FRONTIERS, in which clients are asked a short set of questions during their first encounter with a health provider, may serve this purpose ${ }^{49}$.

g) Work with the INSS to convince EMPs of the importance of postpartum and postabortion family planning.

With respect to the improvement of PMTCT services, we propose that:

a) PMTCT counseling sessions be conducted routinely in the waiting areas of health centers where women are waiting for antenatal care. Results of the study show that health clinics have staff that has been trained to conduct these counseling sessions, but not all women are receiving PMTCT counseling during their antenatal visits. Organizing at least one of these sessions every day may increase the probability that women attend at least one.

b) Inform all women in antenatal care of the tests that they are going to have and give them the choice of opting out of HIV testing. Since most health centers and hospitals perform blood tests on-site, an option may be to prepare a test checklist that testing staff can read to women, and striking those that the client rejects.

c) Organize a workshop in the clinics where HIV+ women receive most of their health care to remind health providers of the importance of family planning in this group and to inform them of eligibility criteria for contraceptive methods in this population. The target population of this workshop should be family planning providers and those involved in the care and treatment of HIV+ users. During this workshop, providers should discuss a mechanism to identify HIV+ men and women with unmet need for family planning and the best way to satisfy these needs.

\footnotetext{
${ }^{48}$ FRONTIERS. 2007. Balanced Counseling Strategy Toolkit, FRONTIERS resource. Washington, DC: Population Council.

${ }^{49}$ Vernon, Ricardo, James R. Foreit, and Emma Ottolenghi. 2006. Introducing Systematic Screening to Reduce Unmet Health Needs: A Manager's Manual, FRONTIERS manual. Washington, DC: Population Council.
} 
Appendix 1. Characteristics of the SILAIS in sample

\begin{tabular}{|l|c|c|c|c|}
\hline SILAIS & Poverty $^{\mathbf{a}}$ & Urbanization $^{\mathbf{b}}$ & $\begin{array}{c}\text { Access to health } \\
\text { services }^{\mathbf{c}}\end{array}$ & HIV $^{\mathbf{d}}$ \\
\hline Boaco & Poor & Rural & Medium & Low \\
\hline Chinandega & Poor & Urban & Medium & High \\
\hline Estelí & Moderate & Urban & High & Low \\
\hline Jinotega & Extreme & Rural & Low & Low \\
\hline Managua & Moderate & Urban & High & High \\
\hline Masaya & Moderate & Urban & Medium & Medium \\
\hline Matagalpa & Poor & Rural & Low & Low \\
\hline RAAN & Extreme & Rural & Low & Medium \\
\hline RAAS & Extreme & Urban & Low & High \\
\hline Rivas & Moderate & Rural & Medium & Medium \\
\hline
\end{tabular}

a "Extreme" means that $90 \%$ or more of the population in the SILAIS had unmet basic needs; "Poor" that between $80 \%$ and $90 \%$ of the population had unmet basic needs; and "Moderate" that less than $80 \%$ of the population had unmet basic needs.

b "Urban" means that $50 \%$ or more of the population lived in a rural community.

c "High" means that the number of physicians per 10,000 inhabitants was greater than five; "medium" that it was between three and five; and "low" that it was less than three.

d "High" means that HIV prevalence was greater than 40 for every 100,000 inhabitants; "medium" that it was between 20 and 40 for every 100,000 inhabitants; and "low" that it was less than 20 per 100,000

Appendix 2. Hospitals, health centers (HC) and EMPs in sample, according to SILAIS

\begin{tabular}{|c|c|c|c|c|}
\hline SILAIS & Hospital & Sentinel HS & $\begin{array}{c}\text { Non-sentinel } \\
\text { HS }\end{array}$ & EMP \\
\hline Boaco & José Nieborowski & Camoapa & Teustepe & \\
\hline Chinandega & Mauricio Abdalah & Villanueva & Corinto & Amocsa \\
\hline Estelí & San Juan de Dios & Estelí & Pueblo Nuevo & \\
\hline Jinotega & Victoria Motta & $\begin{array}{c}\text { Guillermo } \\
\text { Matute }\end{array}$ & Pantasma & \\
\hline Managua & $\begin{array}{l}\text { Bertha Calderón and } \\
\text { Alemán Nicaragüense }\end{array}$ & $\begin{array}{l}\text { Ciudad } \\
\text { Sandino }\end{array}$ & Villa Libertad & $\begin{array}{c}\text { Hospital } \\
\text { Militar and } \\
\text { Salud Integra }\end{array}$ \\
\hline Masaya & Humberto Alvarado & Nindiri & Masatepe & \\
\hline Matagalpa & César Amador Molina & Matagalpa & Río Blanco & \\
\hline RAAN & Nuevo Amanecer & $\begin{array}{l}\text { Puerto } \\
\text { Cabeza }\end{array}$ & Raspan & \\
\hline RAAS & Ernesto Sequira & Bluefields & $\begin{array}{l}\text { Laguna de } \\
\text { Perla }\end{array}$ & \\
\hline Rivas & Gaspar García & Marin Rener & $\begin{array}{l}\text { San Juan del } \\
\text { Sur }\end{array}$ & \\
\hline
\end{tabular}


Appendix 3. Providers' knowledge of the requirements for LAM, according to whether or not they received training on LAM (\%)

\begin{tabular}{|l|c|c|c|}
\hline Condition & $\begin{array}{c}\text { No training } \\
(\mathrm{n}=13)\end{array}$ & $\begin{array}{c}\text { Training } \\
(\mathrm{n}=47)\end{array}$ & $\begin{array}{c}\text { All providers } \\
(\mathrm{n}=60)\end{array}$ \\
\hline Exclusive breastfeeding & 92 & 96 & 95 \\
\hline Baby younger than six months old & 54 & $81^{*}$ & 75 \\
\hline Lack of menstruation & 38 & $77^{*}$ & 68 \\
\hline All three conditions & 31 & $70^{*}$ & 62 \\
\hline
\end{tabular}

* The percentage of providers that know this condition differs significantly $(\mathrm{p}<0.05)$ between providers that received training on LAM and providers that did not receive that training

Source: Structured interviews with health providers involved in family planning services in health centers

\section{Appendix 4. Original Spanish language used in Box 1}

"We still have several questions about breastfeeding. I cannot go and talk to the users if I am not completely convinced because I still have several doubts." (Por ejemplo, quedaron algunas dudas de lactancia materna todavía, o sea yo no puedo ir a hablarles a las personas si yo tal vez no estoy convencida totalmente por las inquietudes que me quedaron.)

"Another problem is that even when you have the resources and the willingness to give counseling, you have a lot of work because of the lack of staff. For instance, if I have ten minutes to be with a patient, it is very unlikely that I will give her good counseling. For example, if I am with a pregnant woman, I have to weigh her, take her blood pressure and conduct an examination; in addition to that, I have to tell her about breastfeeding, risk factors, PMTCT, offer her an HIV test. Plus, I have to see another 24 pregnant women. Because of the time factor you have to prioritize the messages you give."(Hay otro problemita en cuanto a que tal vez uno tiene o el recurso tiene la voluntad de dar una consejería pero tiene recarga de trabajo y entonces por pocos recursos; si yo tengo por ejemplo diez minutos para atender a un paciente, muy difícilmente le voy a brindar una buena consejería, porque si le estoy dando por ejemplo a una embarazada, para atenderla se toma bastante tiempo, porque hay que pesarla, tomarle la presión, hay que examinarla; aparte de eso tengo que hablarle de lactancia materna, tengo que hablarle de factores de riesgo, le tengo que hablar de prevención de transmisión, ofertarle la muestra de VIH, pero aparte de eso tengo 24 embarazadas más que ver; también el factor tiempo impide como en un momento hay que priorizar lo fundamental que tiene que hablar en ese momento.) 
Appendix 5. Factors associated with family planning information during antenatal care: Results of a multivariate logistic regression shown in Box 2

\begin{tabular}{|l|c|c|c|}
\hline \multicolumn{1}{|c|}{ Variable } & Odds-ratio & $\begin{array}{c}\text { Robust } \\
\text { S.E. }\end{array}$ & p \\
\hline Has two or more visits to ANC (ref.) & & & \\
\hline First ANC visit & 0.314 & 0.126 & 0.004 \\
\hline 19 years old or less (ref.) & & & \\
\hline 20-34 years old & 1.415 & 0.319 & 0.123 \\
\hline 35 years old or more & 0.868 & 0.366 & 0.738 \\
\hline Less than university education (ref.) & & & \\
\hline Some university education & 0.472 & 0.172 & 0.040 \\
\hline Single, divorced or widowed (ref.) & & & \\
\hline Married or cohabiting & 1.905 & 0.461 & 0.008 \\
\hline Parity=0 (ref.) & & & \\
\hline Parity=1 & 1.600 & 0.457 & 0.100 \\
\hline Parity=2 to 3 & 1.737 & 0.393 & 0.015 \\
\hline Parity=4 or more & 1.995 & 0.706 & 0.051 \\
\hline MOH hospital (ref.) & & & \\
\hline MOH sentinel health center & 1.017 & 0.316 & 0.957 \\
\hline MOH non-sentinel health center & 0.579 & 0.224 & 0.158 \\
\hline Private (EMP) & 0.209 & 0.075 & 0.000 \\
\hline Facility in moderately poor region (ref.) & & & \\
\hline Facility in poor region & 0.801 & 0.342 & 0.604 \\
\hline Facility in extremely poor region & 0.879 & 0.331 & 0.733 \\
\hline & & & \\
\hline N & 573 & & \\
\hline$\chi^{2}(13)$ & 85.53 & & \\
\hline
\end{tabular}

Note: Robust estimation was used because data is clustered in health establishments

Source: Exit interviews with women in antenatal care 
Appendix 6. Women who have received HIV information during antenatal care, according to number of ANC visits (\%)

\begin{tabular}{|l|c|}
\hline \multicolumn{1}{|c|}{ Number of ANC visits } & $\begin{array}{c}\text { \% who have received HIV } \\
\text { information }\end{array}$ \\
\hline One $(\mathrm{n}=77)$ & 23 \\
\hline Two $(\mathrm{n}=86)$ & 26 \\
\hline Three $(\mathrm{n}=84)$ & 31 \\
\hline Four $(\mathrm{n}=90)$ & 26 \\
\hline Five or more $(\mathrm{n}=232)$ & 31 \\
\hline All women $(\mathrm{n}=569)$ & 28 \\
\hline
\end{tabular}

Note: No statistical differences $(\mathrm{p}<0.10)$ were found between women with different numbers of ANC visits Source: Exit interviews with women in antenatal care

\section{Appendix 7. HIV counseling during antenatal care, according to type of establishment}

\begin{tabular}{|l|c|}
\hline \multicolumn{1}{|c|}{ Type of establishment } & $\begin{array}{c}\text { Women who have received counseling } \\
(\boldsymbol{\%})\end{array}$ \\
\hline Hospital $(\mathrm{n}=222)$ & $31^{*}$ \\
\hline Sentinel health center $(\mathrm{n}=117)$ & 21 \\
\hline Non-sentinel health center $(\mathrm{n}=114)$ & $34^{* *}$ \\
\hline EMP $(\mathrm{n}=143)$ & 21 \\
\hline All women $(\mathrm{n}=596)$ & 27 \\
\hline
\end{tabular}

* Differs from the percentage in sentinel health centers with $\mathrm{p}=0.07$, $\mathrm{p}$-value based on the results from a bi-variate logistic regression. (Not shown)

** Differs from the percentage in sentinel health centers with $\mathrm{p}=0.03$, $\mathrm{p}$-value based on the results from a bi-variate logistic regression. (Not shown)

Source: Exit interviews with women in antenatal care 
Appendix 8. Contraceptive use and willingness to use a method among women in the sixmonth postpartum period

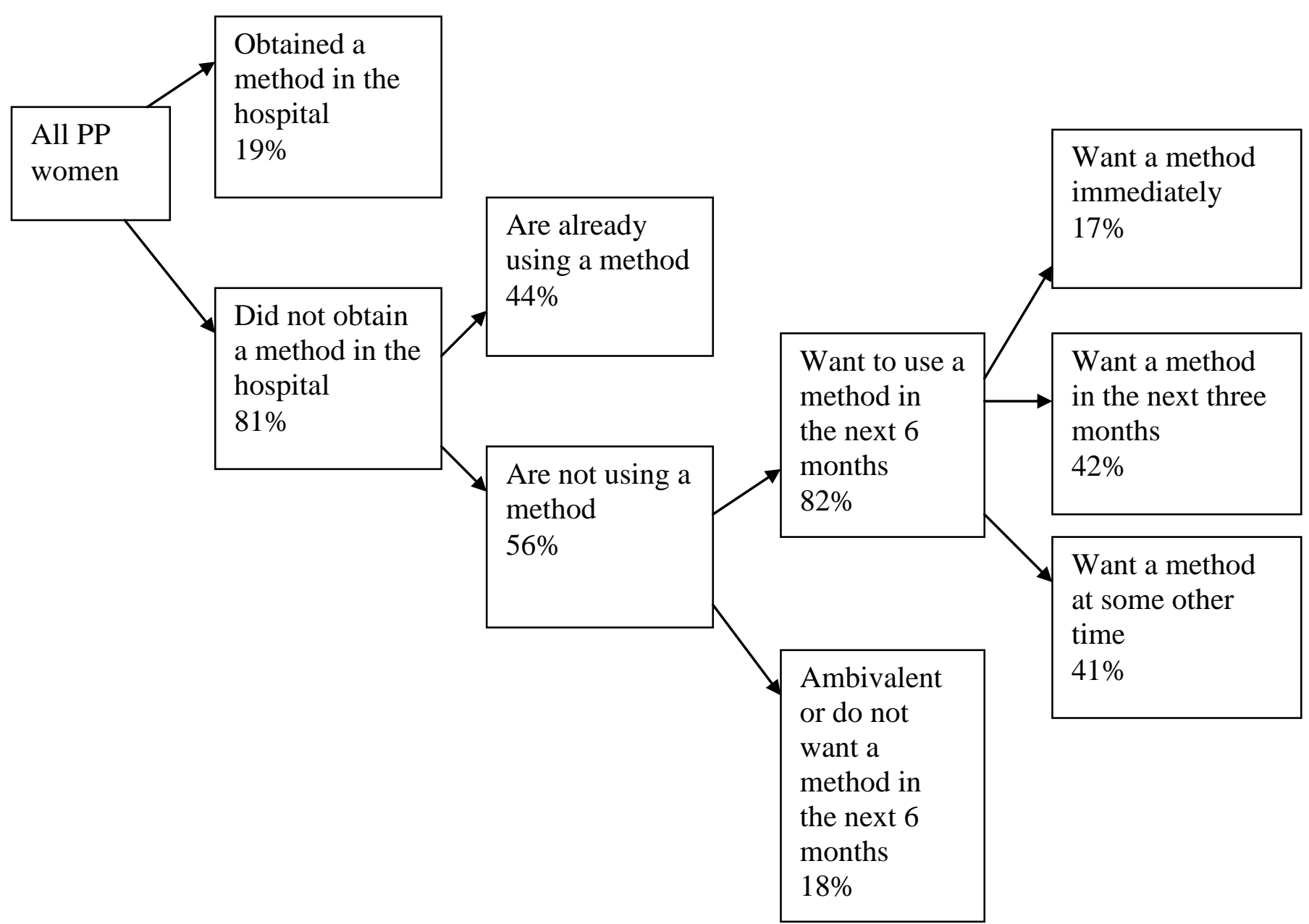

Source: Exit interviews with women in the six-month postpartum period 


\section{Appendix 9. Original Spanish verbatims used in Box 3}

"The first time I came my baby was three months old and my husband was not with me, but they did not want to give me the injection. They told me that I should come back while menstruating. I answered that my husband was not [living] with me. I told her: 'My husband is in another country and I have not had sexual relations, please give it to me.' 'No!,' they told me, and it is until now that I came back." (La primera vez que vine mi bebe tenía tres meses y mi marido no estaba y no me quisieron poner la inyección. Me dijeron, 'Tiene que andar con la regla, si no, no se la pongo'. Entonces le dije yo, es que mi marido no estaba. Él andaba en otro país y yo no he tenido relaciones, póngamela, le dije. No, dicen, y no me la quiso poner y hasta ahora que vuelvo a venir.)

Appendix 10. Risk of an unplanned pregnancy among several groups of women in the sixmonth postpartum period $(\%)$

\begin{tabular}{|c|c|c|}
\hline Women's characteristics & $\begin{array}{c}\% \text { at risk of an unplanned } \\
\text { pregnancy }\end{array}$ & p-value \\
\hline \multicolumn{3}{|c|}{ Residence } \\
\hline Rural $(n=169)$ & 21 & \multirow[t]{2}{*}{0.048} \\
\hline Urban $(n=405)$ & 14 & \\
\hline \multicolumn{3}{|c|}{ Mother tongue } \\
\hline Miskito $(n=33)$ & 30 & \multirow[t]{2}{*}{0.021} \\
\hline Spanish $(n=541)$ & 15 & \\
\hline \multicolumn{3}{|c|}{ Marital status } \\
\hline Single, widowed and divorced $(n=81)$ & 25 & \multirow[t]{2}{*}{0.022} \\
\hline Married or cohabiting $(n=493)$ & 15 & \\
\hline \multicolumn{3}{|c|}{ Parity } \\
\hline One child $(n=251)$ & 15 & \multirow[t]{3}{*}{0.002} \\
\hline Two children $(n=158)$ & 24 & \\
\hline Three or more children & 10 & \\
\hline
\end{tabular}

Source: Exit interviews with women in the six-month postpartum period 
Appendix 11. Factors associated with contraceptive use in the six months postpartum: Results of multivariate logistic regression shown in Box 4

\begin{tabular}{|l|c|c|c|}
\hline \multicolumn{1}{|c|}{ Variable } & Odds-ratio & $\begin{array}{c}\text { Robust } \\
\text { S.E. }\end{array}$ & p \\
\hline Received antenatal care & 1.235 & 0.427 & 0.542 \\
\hline Had a hospital delivery & 1.508 & 0.367 & 0.091 \\
\hline Received FP counseling during ANC & 0.997 & 0.325 & 0.992 \\
\hline $\begin{array}{l}\text { Received FP counseling during hospital } \\
\text { stay for delivery }\end{array}$ & 1.728 & 0.375 & 0.012 \\
\hline $\begin{array}{l}\text { Received FP counseling during post- } \\
\text { delivery visits }\end{array}$ & 1.979 & 0.387 & 0.000 \\
\hline Still in exclusive breastfeeding & 2.190 & 0.783 & 0.028 \\
\hline Menses have not returned & 2.659 & 0.829 & 0.002 \\
\hline$<19$ years old (ref.) & & & \\
\hline 20-35 years old & 0.567 & 0.084 & 0.000 \\
\hline$>35$ years old & 0.570 & 0.325 & 0.324 \\
\hline No formal education (ref.) & & & \\
\hline Primary school & 0.884 & 0.344 & 0.752 \\
\hline Secondary school & 0.743 & 0.277 & 0.426 \\
\hline Some college & 1.039 & 0.411 & 0.922 \\
\hline Married or cohabiting & 3.670 & 1.179 & 0.000 \\
\hline 1 child or less (ref.) & & & \\
\hline Has 2 children & 0.690 & 0.200 & 0.200 \\
\hline Has 3 or more children & 1.625 & 0.312 & 0.011 \\
\hline & & & \\
\hline $\mathrm{N}$ & 602 & & \\
\hline$\chi^{2}(15)$ & 474.06 & & \\
\hline
\end{tabular}

Note: Robust estimation was used because data is clustered in health establishments

Source: Exit interviews with women in the six-month postpartum period 
Appendix 12. Family planning counseling and delivery of a contraceptive method before hospital discharge for delivery, according to selected sociodemographic characteristics

\begin{tabular}{|c|c|c|c|c|}
\hline \multirow{2}{*}{$\begin{array}{c}\text { Women's } \\
\text { characteristics }\end{array}$} & \multicolumn{2}{|c|}{$\begin{array}{l}\text { Received family planning } \\
\text { counseling }\end{array}$} & \multicolumn{2}{|c|}{$\begin{array}{l}\text { Wanted a contraceptive method } \\
\text { and received one }\end{array}$} \\
\hline & $\%$ & p-value & $\%$ & p-value \\
\hline \multicolumn{5}{|c|}{ Type of SILAIS were delivery was had } \\
\hline Urban $(n=316)$ & 60 & \multirow{2}{*}{0.009} & 55 & \multirow{2}{*}{0.023} \\
\hline Rural (n=154) & 72 & & 68 & \\
\hline \multicolumn{5}{|c|}{ Age } \\
\hline$<20$ years old $(n=125)$ & 56 & \multirow{2}{*}{0.001} & 43 & \multirow{2}{*}{0.001} \\
\hline 20 or more $(n=323)$ & 68 & & 68 & \\
\hline \multicolumn{5}{|c|}{ Education } \\
\hline None $(n=48)$ & 77 & (ref.) & 69 & (ref.) \\
\hline Primary $(n=187)$ & 66 & 0.155 & 62 & 0.428 \\
\hline Secondary $(\mathrm{n}=\mathbf{2 0 5})$ & 59 & 0.022 & 55 & 0.105 \\
\hline College $(n=39)$ & 62 & 0.161 & 65 & 0.381 \\
\hline \multicolumn{5}{|c|}{ Parity } \\
\hline $1(n=210)$ & 59 & (ref.) & 52 & (ref.) \\
\hline $2(n=109)$ & 54 & 0.400 & 54 & 0.781 \\
\hline 3 or more $(n=168)$ & 73 & 0.006 & 70 & 0.003 \\
\hline
\end{tabular}

Source: Exit interviews with women who delivered in MOH hospitals and EMPs 
Appendix 13. Contraceptive methods received before hospital stay for delivery, according to age group and parity $(\%)$

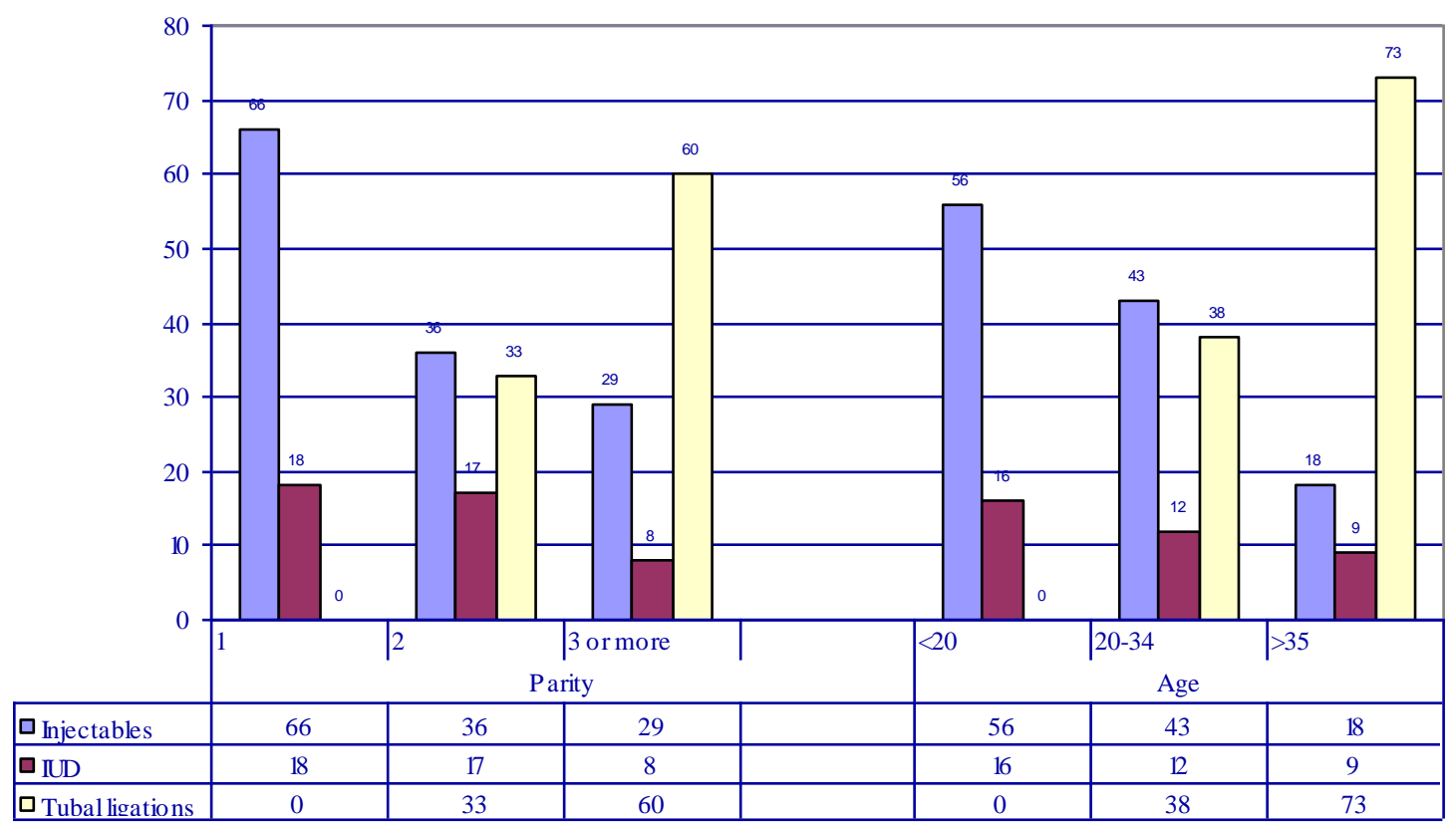

Source: Exit interviews with women who delivered in MOH and EMPs 


\section{Appendix 14. Original Spanish language used in Section VI}

"Well, I knew that I was HIV+ because my husband suffered an accident while working. They started giving him some tests and, because he had a few symptoms, they asked him whether he wanted to be tested for HIV. He was in bed and then I realized that he was HIV+. I was pregnant at the time and I got tested and I got my results at the fourth month. (When asked when she was tested she replies): I was in my first month when I realized that he was HIV+ and I got tested. I did not get my results but until the fourth month." (Bueno, yo me di cuenta a través de mi marido que él trabajaba en el barrio municipal de Masaya, y se cayó, y a raíz de eso comenzaron a hacerle exámenes y le dijeron que si se quería hacer la prueba ya que presentaba síntomas a raíz de eso; él cayó en cama y yo me di cuenta de que él era portador del VIH, y después yo embarazada me hicieron la prueba y me la entregaron a los cuatro meses que tenía de embarazo y no tomaba ningún medicamento. ... Sí, tenía un mes de embarazo cuando me di cuenta que él era portador y me lo dieron a los cuatro meses de embarazo, me entregaron el resultado.)

"No, we don't get treatment or anything. No one in the hospital uses a contraceptive. We use the condom; we don't use any other kind of family planning." (No, no nos mandan tratamiento ni nada; lo único porque de ahí nadie planifica, sólo con el preservativo, no usamos otros métodos de planificación.)

"We used family planning before we were diagnosed with HIV. After our diagnosis, we were told that we should use the condom to prevent mutual reinfection. We weren't told to use other contraceptive methods. We use the male or the female condom and we don't use anything else. Before being diagnosed I used other methods." (O sea la planificación familiar la realizábamos antes que fuéramos diagnosticadas con VIH. Después que ya fuimos diagnosticadas con el virus del VIH, nos dicen, ustedes tienen que usar el preservativo para evitar una reinfección mutuamente, porque no nos dicen que usemos los otros métodos para planificar o usamos el condón masculino o el femenino, para hacer nuestra planificación de ahí ningún otro método más; yo antes de ser diagnosticada usaba otros métodos de planificación)

"The doctor told me that I should not use any other method, that if I used the pill my partner and I could constantly reinfect each other. Then she told me that no other method was of use, and that is why I use the condom. Still, I do not feel confident. There is the risk that the condom will break." (La doctora cuando me dijo no podía usar ningún otro método, usaba otro método podía usar la pastilla pero podíamos estar re infectándonos y si mi pareja no era VIH y yo sí se la iba a pasar, entonces me dijo que no me servía ninguno, solamente éste; por eso es que sólo usamos el preservativo nada más. Es que si se le rompe el preservativo hay un riesgo, no hay seguridad. No me siento tan segura con el preservativo.)

"In my case, I asked when I was diagnosed what method I could use and I was told to use the condom. I asked whether I could continue using the pills or injectables and I was told that it was unnecessary, that if I was using the condom, why should I use another method?" (En mi caso yo pregunté cuando salí diagnosticada y me dijo que usara preservativo. Pero le pregunte si yo podía seguir utilizando las pastillas o las inyecciones; me dijo que no era necesario, que si usaba el preservativo que para qué iba a usar otro método.) 